\title{
Acquisition of "Start" and "Stop" response thresholds in peak-interval timing is differentially sensitive to protein synthesis inhibition in the dorsal and ventral striatum
}

\section{Christopher J. MacDonald ${ }^{1}$, Ruey-Kuang Cheng ${ }^{2}$ and Warren H. Meck ${ }^{3 *}$}

1 Department of Psychology and Center for Memory and Brain, Boston University, Boston, MA, USA

${ }^{2}$ A*STAR/Duke-NUS Neuroscience Research Partnership, National University of Singapore, Singapore

${ }^{3}$ Department of Psychology and Neuroscience, Duke University, Durham, NC, USA

\section{Edited by:}

Valerie Doyere, Centre National de la

Recherche Scientifique, France

Reviewed by:

Joshua D. Berke, University of Michigan, USA

Michael Drew, University of Texas at Austin, USA

\section{*Correspondence:}

Warren H. Meck, Department of Psychology and Neuroscience,

Duke University, 572 Research

Drive, Durham, NC 27708, USA.

e-mail:meck@psych.duke.edu
Time-based decision-making in peak-interval timing procedures involves the setting of response thresholds for the initiation ("Start") and termination ("Stop") of a response sequence that is centered on a target duration. Using intracerebral infusions of the protein synthesis inhibitor anisomycin, we report that the acquisition of the "Start" response depends on normal functioning (including protein synthesis) in the dorsal striatum (DS), but not the ventral striatum (VS). Conversely, disruption of the VS, but not the DS, impairs the acquisition of the "Stop" response. We hypothesize that the dorsal and ventral regions of the striatum function as a competitive neural network that encodes the temporal boundaries marking the beginning and end of a timed response sequence.

Keywords: timing and time perception, decision-making, reward prediction, cortico-striatal circuits, dopamineglutamate interactions, memory consolidation, protein synthesis inhibitors

\section{INTRODUCTION}

Throughout their daily routines, humans and other animals perceive events as a function of the flow of time and make decisions based upon the relative durations of those events by means of a process known as scalar timing (Gibbon et al., 1984; Meck, 2003; Buhusi and Meck, 2005; Buhusi et al., 2009). Therefore, it is perhaps not surprising that timing and time perception within the seconds-to-minutes range-i.e., interval timing-plays a fundamental role in adaptive behavior, including optimal foraging, temporal discounting, and other aspects of intertemporal preferences and neuroeconomics (Brunner et al., 1992; Bateson, 2003; Zauberman et al., 2009; Cui, 2011; Ray and Bossaerts, 2011). Indeed, interval timing contributes importantly to decisionmaking as well as learning predictive relationships among stimuli in both appetitive and aversive contexts (Gibbon et al., 1997; Gallistel and Gibbon, 2000; Harrington et al., 2004; Tanaka et al., 2004; Maimon and Assad, 2006; Droit-Volet and Meck, 2007; Meck and MacDonald, 2007; Forstmann et al., 2008; Jones et al., 2011). In fact, temporal discounting and the anticipation of a future event's time of occurrence often emerge as critical variables that influence performance during tasks intended to characterize a variety of basic cognitive processes, including memory (Malapani et al., 1998; Lustig et al., 2005; Lustig and Meck, 2005, 2011), attention (Lustig and Meck, 2001; Buhusi and Meck, 2002, 2006, 2009a,b; Meck and Benson, 2002; Coull et al., 2004), choice (Fantino et al., 1979; McClure et al., 2004; Rudebeck et al., 2006), and reaction time (MacDonald and Meck, 2004, 2006).

Although dopamine-glutamate interactions within corticostriatal circuits have been shown to support numerous aspects of interval timing (Meck, 1983, 1996, 2006a,b; Matell et al., 2004; Liao and Cheng, 2005; Cheng et al., 2006, 2007a,b,c; Drew et al., 2007; Pennartz et al., 2009; Meck et al., 2008, 2012; Williamson et al., 2008; Agostino et al., 2011; Coull et al., 2011; Gu et al., 2011; Hata, 2011; Höhn et al., 2011; Jones and Jahanshahi, 2011; Allman and Meck, 2012), it remains unclear what types of neural mechanisms are involved in the construction of decision thresholds for determining when to start and stop responding (see Meck, 2002, 2006c; Vink et al., 2005; Bromberg-Martin et al., 2010; van der Meer et al., 2010). In order to investigate this issue, we employed the peak-interval (PI) timing procedure which is a "classic" example of a duration reproduction task that has proven useful in the study of temporal cognition due to its applicability across a wide-variety of animal species_-including fish, birds, rodents, and primates (Church et al., 1991, 1994; Rakitin et al., 1998; Paule et al., 1999; Buhusi and Meck, 2000; Buhusi et al., 2002, 2009; Gallistel et al., 2004; Hinton and Meck, 2004; Drew et al., 2005, 2007; Penney et al., 2008; Ward et al., 2009, 2012; Cheng et al., 2011) and stimulus modalities (Meck and Church, 1982; Meck, 1991; Penney et al., 2000; Bueti, 2011; Lustig and Meck, 2011; Allman and Meck, 2012). In the PI timing procedure, the subject is initially exposed exclusively to fixed-interval (FI) trials throughout a session, during which the onset of a signal (e.g., houselight) reliably predicts the time at which feedback/reward will be provided-thus establishing a temporal criterion. After sufficient training with FI trials, unreinforced probe trials are randomly intermixed within a session in order to characterize the accuracy and precision of temporal memory as illustrated in Figure 1A. During a probe trial, the signal stays on long past the temporal criterion and no feedback is provided. Following sufficient training with probe trials, the mean response rate for an individual subject averaged across all probe trials within a session resembles a Gaussian-shaped distribution-the peak functionwhose mode is centered on the temporal criterion (Meck and Church, 1984; Church et al., 1994; Rakitin et al., 1998). In such 


\section{A \\ The peak-interval procedure Composed of two trial types randomly intermixed throughout the session}
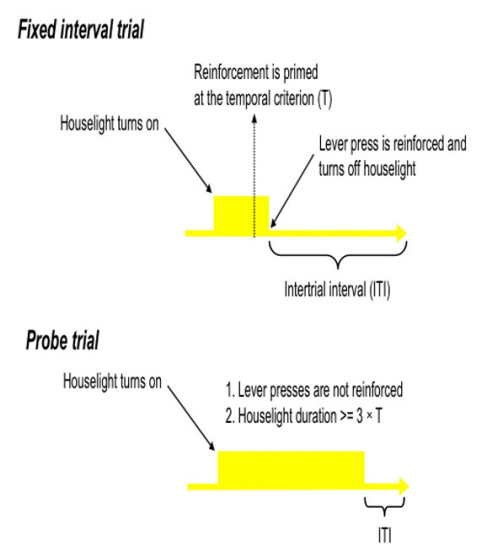

Probe trial responses are used to compute the peak function as well as the Starts and Stops

\section{Houselight turns on<smiles>[3H][3H]</smiles>
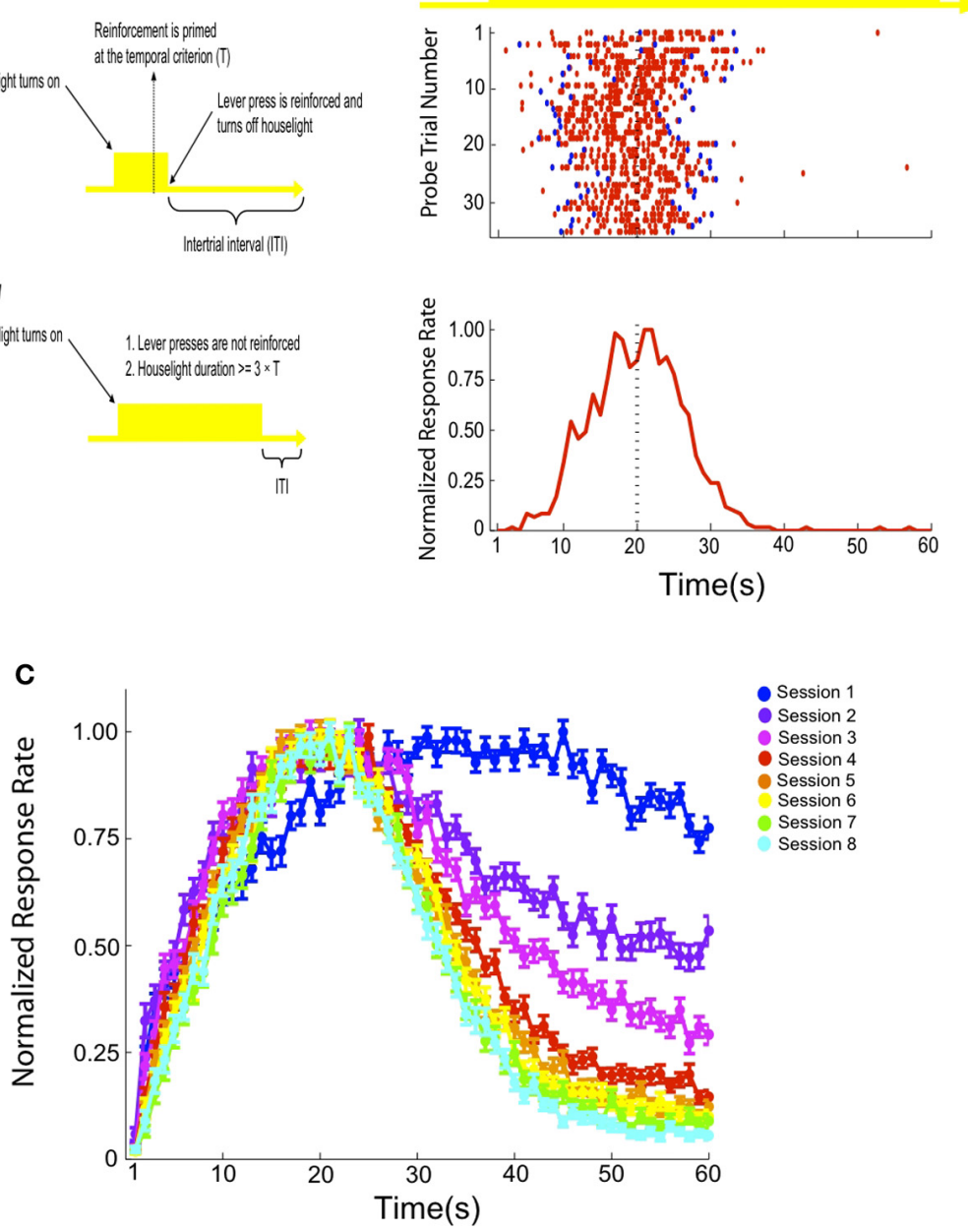

FIGURE 1 | (A) An illustration depicting the two trial types randomly intermixed throughout a standard peak-interval (PI) training session. The houselight serves as the signal being timed in this example. On FI trials, the houselight's onset predicts the availability of reinforcement at 20 s. Delivery of reward is contingent on a lever press made by the rat at or after this time, which also terminates the houselight and initiates an ITI. On probe trials, the houselight remains on for an extended period of time with a minimum of $60 \mathrm{~s}$ and reinforcement is never delivered. (B) A representative rat that is well-trained on the PI procedure. The raster plot (top) depicts each probe trial as a row and responses (red tics) are displayed across time during the probe trial. On each trial, a response sequence contains both a "Start" and "Stop" response (blue tics), which demarcates the beginning ("Start") and end ("Stop") of the "high state" (see Introduction and Methods). Probe trial responses are collapsed across trials within $1 \mathrm{~s}$ bins to create the peak function, which is normalized so that it expresses the percentage of maximum response rate as a function of signal duration (bottom). Because the signal extends well past the temporal criterion (e.g., 20 s), the accuracy and precision of the remembered time of reward is inferred by the rat's response rate before and after $20 \mathrm{~s}$. (C) Before probe trials are randomly intermixed within a session, rats are exposed only to FI trials for multiple sessions (see Methods). This panel depicts a normalized peak function ( \pm SEM) averaged across all rats during the first eight sessions in which probe trials are randomly intermixed with FI trials. Note that the degree of response inhibition after the remembered time of reward increases across sessions as the rats obtain more experience with partial extinction during unreinforced probe trials. cases, a balance is often struck between starting the sequence of reinforced behavior in anticipation of the reward, but also giving up responding when the opportunity for reward is thought to have passed (Brunner et al., 1992, 1996, 1997; Bateson, 2003; Silva and Timberlake, 2005).
With rats and pigeons, for whom an appetitive reward can readily serve as a time marker (Freestone and Church, 2010), performance during a single probe trial can be described by an abrupt transition both into and out of a "high state" of responding, during which the subject responds at a relatively rapid, 
constant rate as illustrated in Figure 1B. Remarkably, the variability in the onset ("Start") and offset ("Stop") of the "high state," as well as the duration of the "high state" itself, is proportional to the interval being timed (Church et al., 1994; Rakitin et al., 1998). This feature contributes to the scalar property, which describes the proportionality between the spread of the peak function and the value of the temporal criterion (i.e., Weber's law-Gibbon et al., 1984; Cheng and Meck, 2007). Importantly, the "Start" and "Stop" times are considered independent of one another because they are not well correlated on a trial-by-trial basis (Church et al., 1994; Gallistel et al., 2004; Matell et al., 2006; Buhusi and Meck, 2009b). In effect, these "Start" and "Stop" times are independent decision thresholds demarcating an action sequence that the subject "attempts" to center on the expected time of reward. Moreover, the presentation of unreinforced probe trials subsequently leads to the acquisition of the "Stop" response threshold (see Balci et al., 2009). At steady-state levels of performance this action sequence may be conceptualized as a distinct behavioral unit whose organization depends on the memory of the target duration (see Gibbon et al., 1984; Church et al., 1994).

However, despite the evidence supporting a clear dissociation between "Start" and "Stop" times, there has been no anatomical localization of these response thresholds for interval-timing tasks (see Mansfield et al., 2011). In addition, there is little understanding concerning (1) how the "Start" and "Stop" thresholds are acquired and (2) the underlying neural substrates for temporal conditioning (Gallistel and Gibbon, 2000). Regarding the first point, in the PI timing procedure the subject must learn to inhibit responding after the target duration during probe trials, which ultimately leads to the gradual acquisition of the "Stop" response as illustrated by the PI data from Experiment 1 plotted in Figure 1C. This occurs when partial extinction/unrewarded probe trials are first introduced, typically long after the emergence of the "Start" response which defines the beginning of the "high state" of responding acquired during initial FI training. Regarding the second point, there is reason to believe that the striatum is an important neural substrate for interval timing in a wide variety of timing procedures (Gibbon et al., 1997; Matell and Meck, 2000, 2004; Buhusi and Meck, 2005; Meck, 2006b; Harrington et al., 2011a,b; Kotz and Schwartze, 2011; Matell et al., 2011; Portugal et al., 2011; van Rijn et al., 2011). Indeed, the firing rate of neurons in the dorsal striatum (DS) is modulated with respect to the temporal criterion acquired in the PI timing procedure (Matell et al., 2003). Outside the context of interval timing, one proposed function of the DS is organizing the hierarchical structure of learned response sequences (Graybiel, 1998; Fujii and Graybiel, 2005; Jin et al., 2009; Jin and Costa, 2010), which is consistent with a direct relationship to interval timing. For example, single neurons within the rat's DS also encode the hierarchal context of a specific response within a systematic, natural response sequence like grooming (Aldridge and Berridge, 1998) and lesions of the DS can disrupt the expression of both natural and learned sequences (Cromwell and Berridge, 1996; Bailey and Mair, 2006). While the DS is believed to contribute to encoding of the temporal criterion, the ventral striatum (VS) is thought to play a modulatory role for interval timing, especially with respect to changes in the reward value associated with feedback at the temporal criterion
(McClure et al., 2004; O’Doherty et al., 2004; MacDonald and Meck, 2005; Meck, 2006b). This connection is consistent with a broader framework for understanding VS function in which this region of the striatum appears to hold a closer relationship to affective processing than the DS and plays a role in "behavioral flexibility" by modulating ongoing natural and/or learned behaviors (Cardinal et al., 2002; Kelley, 2004; Pleil et al., 2011). For example, the VS contribute to inhibiting behavior that is made inappropriate so that novel behavioral strategies may be acquired (Tanaka et al., 2004, 2007; Floresco et al., 2006).

With these functional parallels in mind, we were interested in characterizing the role of the DS and VS in the PI timing procedure while rats acquired the "Start" and "Stop" responses. Learning entails enduring changes in the brain, which presumably requires a cascade of molecular events to take place beforehand (Abel and Lattal, 2001). Protein synthesis inhibitors, such as anisomycin (ANI), have proven to be useful tools for the characterization of this memory consolidation process in Pavlovian conditioning (Stafford and Lattal, 2009), spatial navigation (Morris et al., 2006), instrumental learning (Hernandez et al., 2002), and motor-skill acquisition (Wächter et al., 2010). In the following experiments, we used ANI microinjections administered prior to rats performing on variants of the PI timing procedure to conclude that the acquisition of the "Start" response depends on normal functioning (including protein synthesis) within the DS during training (see Castellucci et al., 1989; Okamoto et al., 2011). In contrast, disruption of normal functioning within the VS during training, but not the DS, impairs the acquisition of the "Stop" response.

\section{MATERIALS AND METHODS ANIMALS}

Across both experiments, a total of 49 experimentally naïve Sprague-Dawley rats (Charles-River Laboratories, Raleigh, NC) weighing between 250-350 g at the start of the experiment were used. Rats were housed in pairs in a 12:12 light:dark cycle with lights on from 7:00 AM to 7:00 PM. Rats were given continuous access to water and maintained at $85 \%$ free-feeding weight with a daily ration of rat chow (Rodent Diet 5001, PMI Nutrition International, Inc., Brentwood, MO) given shortly after the test session. All procedures were conducted in accordance with the policies of the Duke University Institutional Animal Care and Use Committee.

\section{APPARATUS}

The apparatus consisted of 10 standard lever boxes (Model ENV007, MED Associates, Inc., Albans, VT) housed in light and sound attenuating cubicles (Model ENV-019, MED Associates, Inc., Albans, VT). Each lever box had inside dimensions of approximately $24 \mathrm{~cm} \times 31 \mathrm{~cm} \times 31 \mathrm{~cm}$. The top, side walls, and door were constructed of clear acrylic plastic. The front and back walls were constructed of stainless steel, and the floor was comprised of 19 parallel stainless steel bars. Each lever box was equipped with two retractable response levers (Model ENV-112, MED Associates, Inc., Albans, VT) situated on opposite sides of the front wall of the lever box. Precision food pellets ( $45 \mathrm{mg}$-Research Diets, Inc., New Brunswick, NJ) could be delivered by a pellet dispenser (Model ENV-203, MED Associates, Inc., Albans, VT) to a food 
cup on the front wall, $1 \mathrm{~cm}$ above the floor, and in between the two levers. A $28 \mathrm{~V}, 100 \mathrm{~mA}, 2500 \mathrm{~lx}$ house light was mounted at the center-top of the front wall and could be used to illuminate the box. A white noise amplifier/speaker system (Model ENV-225, MED Associates, Inc., Albans, VT) was mounted on the opposite wall from the levers but was not used. A $66 \mathrm{~dB}$ sound produced by a ventilation fan was present throughout all procedures.

\section{SURGERY}

Rats were anesthetized with i.p. injections of both ketamine hydrochloride $(100 \mathrm{mg} / \mathrm{kg})$ and xylazine hydrochloride $(20 \mathrm{mg} / \mathrm{kg})$. Bilateral guide cannluae (Plastics One Inc., 26 gauge with stylets) were implanted into either the DS $(A=1.2 \mathrm{~mm}, L= \pm 2.5 \mathrm{~mm}, V=4.1 \mathrm{~mm})$ or VS $(A=1.6 \mathrm{~mm}$, $L= \pm 1.9 \mathrm{~mm}, V=-6.3 \mathrm{~mm}$ ). The tips of the injector cannulae extended $\sim 1.5 \mathrm{~mm}$ from the base of the guide cannulae. The cannulae were fixed using dental cement and three small, skull screws. All rats were given at least five days of recovery.

\section{HISTOLOGY}

In order to confirm cannulae placement, following the experiment, all rats were perfused transcardially with $0.9 \%$ saline followed by $10 \%$ formalin. Brains were removed and stored in a $10 \%$ formalin solution before being transferred to a $10 \%$ formalin-sucrose solution before sectioning.

\section{DRUGS AND INFUSIONS}

ANI (Sigma-Aldrich, St Louis, MO) was dissolved in equimolar $\mathrm{HCl}$ and diluted with CSF (Harvard Apparatus, Holliston, ME-Experiment 1) or $0.9 \%$ saline (Sigma-Aldrich, St Louis, $\mathrm{MO}$-Experiment 2), and adjusted to $\mathrm{pH} 7$ with $\mathrm{NaOH}$ for a final concentration of $62.5 \mu \mathrm{g} / 0.5 \mu \mathrm{l}$. The ANI dose was selected based on preliminary data from our laboratory and a previous study that confirmed it as being an effective dose for behavioral tasks of this sort (Hernandez and Kelley, 2004). In memory consolidation experiments, protein synthesis is often inhibited after training is completed. Depending on the experimental question, this strategy can be especially effective when using tasks that require a limited numbers of trials (e.g., contextual fear conditioning) to meet some learning criteria. However, learning the "Stop" response requires multiple daily sessions that each include 60 or more total trials/session (Figure 1C). Because of this we couldn't be sure which specific trial or trials within the session constitute the "learning episode" as well as when the "Start" and "Stop" response thresholds are consolidated (or in fact whether these task components are reconsolidated at any point during the session). As a consequence, we chose to infuse ANI before the training session began in order to ensure that protein synthesis was maximally impaired throughout the session (see Wanisch and Wotjak, 2008 for data on the time course of protein synthesis inhibition).

All rats were given at least three days of mock infusions to habituate them to the injection procedure before testing. Bilateral infusions were given immediately before the sessions at a rate of $0.25 \mu \mathrm{l} / \mathrm{min}$ over the course of two minutes. Following the infusion, the injector cannulae were maintained in place for at least $1 \mathrm{~min}$ before being placed immediately in the lever box to begin the experiment.

\section{EXPERIMENT 1: BEHAVIORAL TRAINING: EFFECTS OF ANISOMYCIN INFUSION ON "START" AND "STOP” RESPONSES DURING THE ACQUISITION OF A PEAK-INTERVAL (PI) 20 S RESPONSE SEQUENCE Pre-training (Sessions 1-5)}

All rats received six sessions of combined magazine and lever training. During these sessions, a food pellet was delivered once a min for $60 \mathrm{~min}$, and was signaled at the $58 \mathrm{~s}$ mark by a $2 \mathrm{~s}$ lever retraction/extension sequence. Throughout the session, a lever press also resulted in the delivery of a food pellet.

\section{Fixed-interval (FI) 20 s training (Sessions 6-55)}

During FI 20 s training, trials were cued by the onset of a houselight and extension of the response lever for the duration of the trial. Any lever press before $20 \mathrm{~s}$ had no consequence. However, any lever press after $20 \mathrm{~s}$ resulted in (1) delivery of a food pellet, (2) offset of the houselight, (3) retraction of the lever, and (4) the beginning of an intertrial interval (ITI). An ITI was always $60 \mathrm{~s}$ plus a duration randomly selected from one of seven values $(\min =1.1 \mathrm{~s}, \max =70.4 \mathrm{~s})$ that were geometrically distributed. A new trial began at the end of an ITI and sessions lasted for approximately $2 \mathrm{~h}$.

\section{Post-surgical fixed-interval (FI) 20 s training (Sessions 56-65)}

Following surgery, rats were given 10 additional sessions of FI training to ensure stable pre-treatment performance for the groups.

\section{Peak-interval (PI) 20 s training (Sessions 66-80)}

PI 20 s training consisted of 50\% FI trials (see above) and 50\% unreinforced probe trials. On any given trial, the chosen trialtype was random. Probe trials were like FI trials except that (1) lever presses after $20 \mathrm{~s}$ did not result in delivery of a food pellet and (2) the houselight remained on and the lever extended for $60 \mathrm{~s}$ plus a duration randomly selected from one of seven values $(\min =1.1 \mathrm{~s}, \max =70.4 \mathrm{~s})$ that were geometrically distributed. The end of a trial signaled the beginning of an ITI, whose parameters were the same as that described during FI training and sessions lasted approximately $2 \mathrm{~h}$. Rats were microinjected with the appropriate solution (ANI or vehicle) $10 \mathrm{~min}$ prior to the beginning of the first 6 PI 20 s training sessions.

\section{EXPERIMENT 2: EFFECTS OF ANISOMYCIN INFUSION ON "START" RESPONSES DURING THE TRANSITION FROM $20 \mathrm{~S}$ TO $50 \mathrm{~S}$ TEMPORAL CRITERION \\ Pre-training (Sessions 1-5)}

All rats received six sessions of combined magazine and lever training. During these sessions, a food pellet was delivered once a min for $60 \mathrm{~min}$, and was signaled at the $58 \mathrm{~s}$ mark by a $2 \mathrm{~s}$ lever retraction/extension sequence. Throughout the session, a lever press also resulted in the delivery of a food pellet.

\section{Fixed-interval (FI) 20 s training (Sessions 6-20)}

During FI training, trials were cued by the onset of a houselight and extension of the response lever. Any lever press before $20 \mathrm{~s}$ had no consequence. However, any lever press after $20 \mathrm{~s}$ resulted in (1) delivery of a food pellet, (2) offset of the houselight, (3) retraction of the lever, and (4) the beginning of an ITI. An ITI was always $60 \mathrm{~s}$ plus a duration randomly selected from one of seven values 
$(\min =1.1 \mathrm{~s}, \max =70.4 \mathrm{~s})$ that were geometrically distributed. A new trial began at the end of an ITI and sessions lasted for approximately $2 \mathrm{~h}$.

\section{Peak-interval (PI) 20 s training (Sessions 21-35)}

PI 20 s training consisted of 50\% FI trials (see above) and 50\% unreinforced probe trials. On any given trial, the chosen trialtype was random. Probe trials were similar to FI trials except that (1) lever presses after $20 \mathrm{~s}$ did not result in delivery of a food pellet and (2) the houselight remained on and the lever extended for $60 \mathrm{~s}$ plus a duration randomly selected from one of seven values $(\min =1.1 \mathrm{~s}, \max =70.4 \mathrm{~s})$ that were geometrically distributed . The end of a trial signaled the beginning of an ITI, whose parameters were the same as that described during FI training and sessions lasted approximately $2 \mathrm{~h}$.

\section{Post-surgical peak-interval (PI) 20 s training (Sessions 36-50)}

Following surgery, rats were given 15 additional sessions of PI $20 \mathrm{~s}$ training to ensure stable pre-treatment performance for each of the groups.

\section{Transition: peak-interval (PI) 50 s training (Sessions 51-90)}

PI $50 \mathrm{~s}$ training was similar to PI $20 \mathrm{~s}$ sessions except that (1) the temporal criterion was extended to $50 \mathrm{~s}$ and (2) probe trials lasted $120 \mathrm{~s}$ plus a duration randomly selected from one of seven values $(\min =1.1 \mathrm{~s}, \max =70.4 \mathrm{~s})$ that were geometrically distributed. Rats were microinjected with the appropriate solution (ANI or vehicle) 10 min prior to the beginning of the first 10 PI 50 s training sessions (see Meck et al., 1984b for additional details concerning the transition from one temporal criterion to another).

\section{DATA ANALYSIS}

The time of each lever press was recorded to an accuracy of $10 \mathrm{~ms}$ and placed into $1 \mathrm{~s}$ time bins. Peak functions were generated by normalizing response rates to the time bin with the highest response rate. The single-trials analysis used has been described elsewhere (Church et al., 1994; Matell et al., 2006). Briefly, in a single trial, the "high state" is determined by fitting three contiguous, but non-overlapping horizontal lines to the response series over time during a single trial. Therefore, the slope of each line represents a response rate over an interval that is defined by the length of the line on the abscissa. The goal is to iteratively maximize the difference between the response rate defined by the middle horizontal line ("high state") and the response rate defined during the flanking horizontal lines. This calculation effectively fits a boxcar-like step function. The "Start" and "Stop" times of this response sequence are defined as the points in the fitted function at which the "high state" begins and ends, respectively.

\section{RESULTS}

\section{Experiment 1: acquisition of the "Stop" response is impaired by anisomycin infusion in the ventral striatum, but not the dorsal striatum}

Because the VS has been observed to contribute to learning and response inhibition within a variety of experimental contexts, the current study was designed to test whether the acquisition of a temporally controlled "Stop" response requires normal functioning (including protein synthesis) in the VS, but not the DS. Thirty rats were trained on a $20 \mathrm{~s}$ PI procedure. Depending on the group assignment, rats were microinjected with ANI (DSANI, $n=7$; VS-ANI, $n=7$ ) or vehicle solution (DS-CON, $n=8$; DS-CON, $n=8$ ) before the first six sessions during which probe trials were first introduced in a training session. We divided the data into two blocks and calculated the mean peak functions for treatment groups during these blocks.

Figure 2 illustrates the mean peak functions (left column) and results of the single-trials analysis (right column) for the CON treatment groups combined over the DS and VS conditions as well as the ANI treatment groups for the separate DS and VS conditions. In each case, the acquisition data are plotted in blocks of 3 sessions (rows), ANI Sessions 1-3 and ANI Sessions 4-6. The data from the CON rats for the DS and VS conditions were combined because there were no reliable differences between these two groups for the "Start" measures during sessions 1-3 $\left(t_{1,40}=0.61, p>0.05\right)$ and sessions $4-6\left(t_{1,22}=1.17, p>0.05\right)$, as well as for the "Stop" measures during sessions $1-3\left(t_{1,40}=\right.$ $0.01, p>0.05)$ and sessions $4-6\left(t_{1,22}=1.96, p>0.05\right)$. A OneWay ANOVA was conducted on the single-trial "Stop" times for ANI Sessions 1-3 and ANI Sessions 4-6. During ANI Sessions $1-3$, there was no reliable effect of Treatment on the "Stop" times $\left(F_{2,87}=0.76, p>0.05\right)$. However, during ANI Sessions $4-6$, there was a significant effect of Treatment $\left(F_{2,69}=11.32\right.$, $p<0.0001)$. Post-hoc tests [Fischer's Least Significant Difference (LSD), $\alpha=0.05$ ] confirmed that the VS-ANI group differed significantly from both the CON and DS-ANI groups in terms of the time of the "Stop" response. No other significant differences were confirmed, i.e., there were no significant differences between the CON-DS and ANI-DS groups or the CON-VS and ANI-VS groups, $p$ 's $>0.05$.

\section{During acquisition of the "Stop" response, anisomycin infusion in the dorsal striatum resulted in a more precise "Start" response}

A similar One-Way ANOVA was used to determine the effect of Treatment on the single-trial "Start" response times. During ANI Sessions 1-3, there was no reliable effect of Treatment on the "Start" times $\left(F_{2,87}=1.12, p>0.05\right)$, however, during ANI Sessions 4-6, a significant effect of Treatment on "Start" times was observed $\left(F_{2,69}=5.13, p<0.01\right)$. Post-hoc tests (Fischer's LSD, $\alpha=0.05)$ confirmed that only the DS-ANI treatment group differed from both the CON and VS-ANI treatment groups. With respect to the expected time of reward, the DS-ANI treatment group withheld responding to a greater degree beginning from the onset of a probe trial. Therefore, rats in the DS-ANI treatment group entered the "high state" at a time that was significantly closer to the target duration, which suggests an increase in temporal precision (Church et al., 1991). The significant main effects observed during ANI Sessions 4-6 continued to be observed during post-ANI Sessions 1-3 during which no ANI treatments were given, $F_{2,69}=10.29, p<0.0001$ and $F_{2,69}=10.52, p<0.0001$ for "Start" and "Stop" response times, respectively.

The differential effects of ANI infusion on the acquisition of "Stop" response were essentially non-existent following extended training without ANI treatment as demonstrated by the lack of 


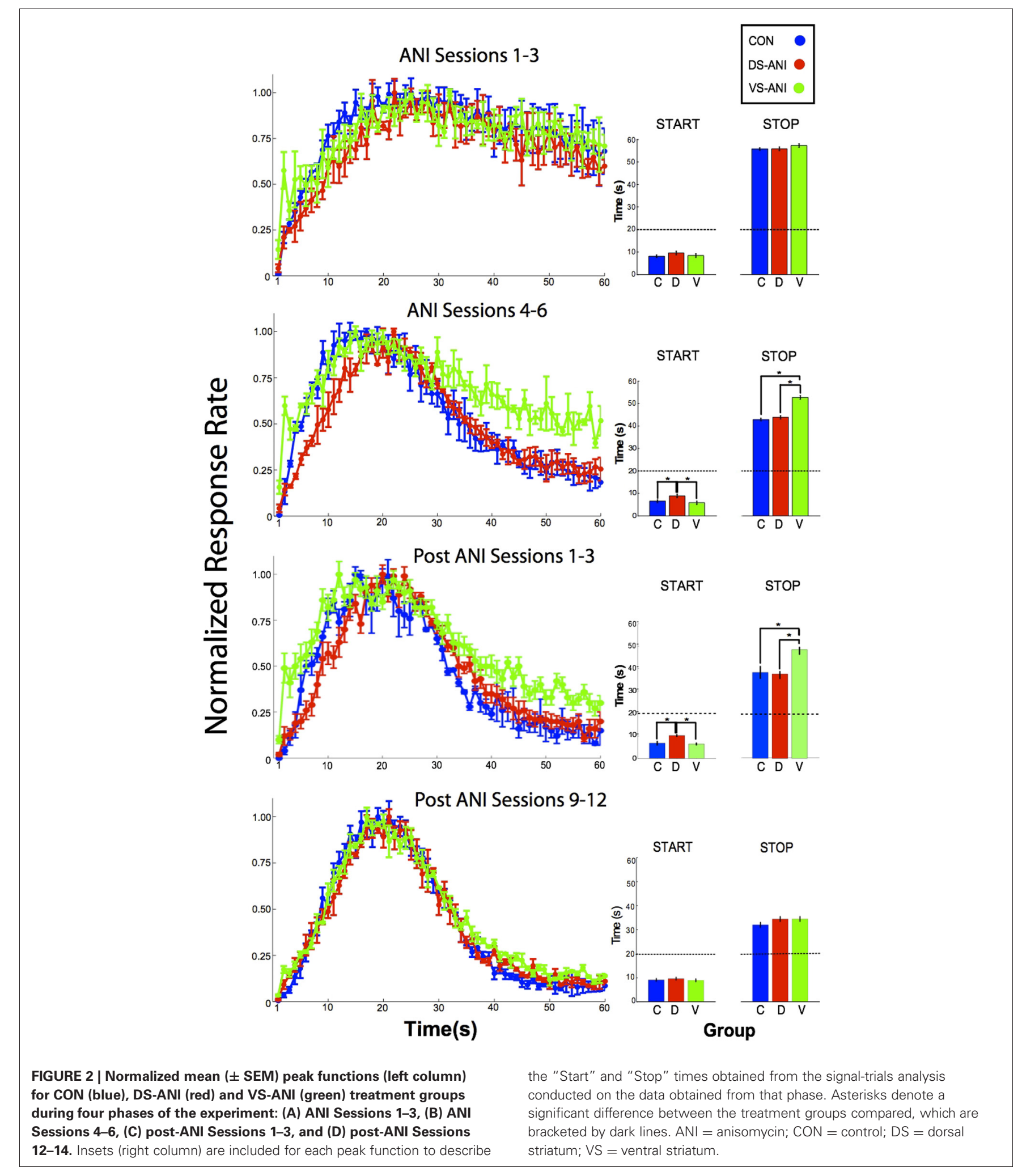

effect on the mean peak functions and the single-trials analysis of "Start" and "Stop" responses during post-ANI Sessions 12-14 (see bottom row of Figure 2). A One-Way ANOVA conducted on both the "Start" and "Stop" times during these post-ANI
Sessions using Treatment condition as the main factor confirmed non-significant effects on both the "Start" and "Stop" measures, $\left(F_{2,69}=0.37, p>0.05\right)$ and $\left(F_{2,69}=1.87, p>0.05\right)$, respectively. These observations indicate that although the effects of 
ANI lingered for a few sessions following its discontinuation (e.g., post-ANI Sessions 1-3), it did not damage the brain in a way that permanently disrupted the temporal control of behavior.

\section{Anisomycin treatment lowered response rates to a comparable degree in both the dorsal striatum and ventral striatum treatment groups, but had no long-lasting effects on timing behavior}

Mean $( \pm$ SEM) response rate during probe trials for CON, DSANI, and VS-ANI treatment groups is plotted as a function of the six ANI microinjection sessions in Figure 3. A Two-Way ANOVA was conducted on the mean response rates during probe trials for each treatment group in order to verify the stability of the response rate across sessions. There was a significant effect of Treatment $\left(F_{2,142}=10.89, p<0.0001\right)$, but non-significant effects of Session $\left(F_{5,142}=0.99, p>0.05\right)$ and the Treatment $\times$ Session interaction $\left(F_{10,142}=0.32, p>=0.05\right)$. Post-hoc tests (Fischer's LSD, $\alpha=0.05$ ) confirmed that only the CON treatment group differed significantly from the DS-ANI $\left(F_{1,142}=16.54\right.$, $p<0.0001)$ and VS-ANI treatment groups $\left(F_{1,142}=16.30, p<\right.$ $0.0001)$, whereas the DS-ANI and VS-ANI treatment groups did not differ reliably from one another $\left(F_{1,142}=0.0001, p>\right.$ 0.05). Overall, the effect of ANI administration was to reduce responding to $\sim 60 \%$ of the levels observed in the CON treatment group $\left(S_{\mathrm{CON}}=0.26, S_{\mathrm{DS}-\mathrm{A}}=0.15, S_{\mathrm{VS}-\mathrm{A}}=0.15\right)$-although this effect did not change substantially across sessions. This finding further supports a reliable dissociation between the response rate index and measurements that characterize the precision of temporal memories (Roberts, 1993; Cheng and Meck, 2007). While the response rate in both ANI treatment groups decreased

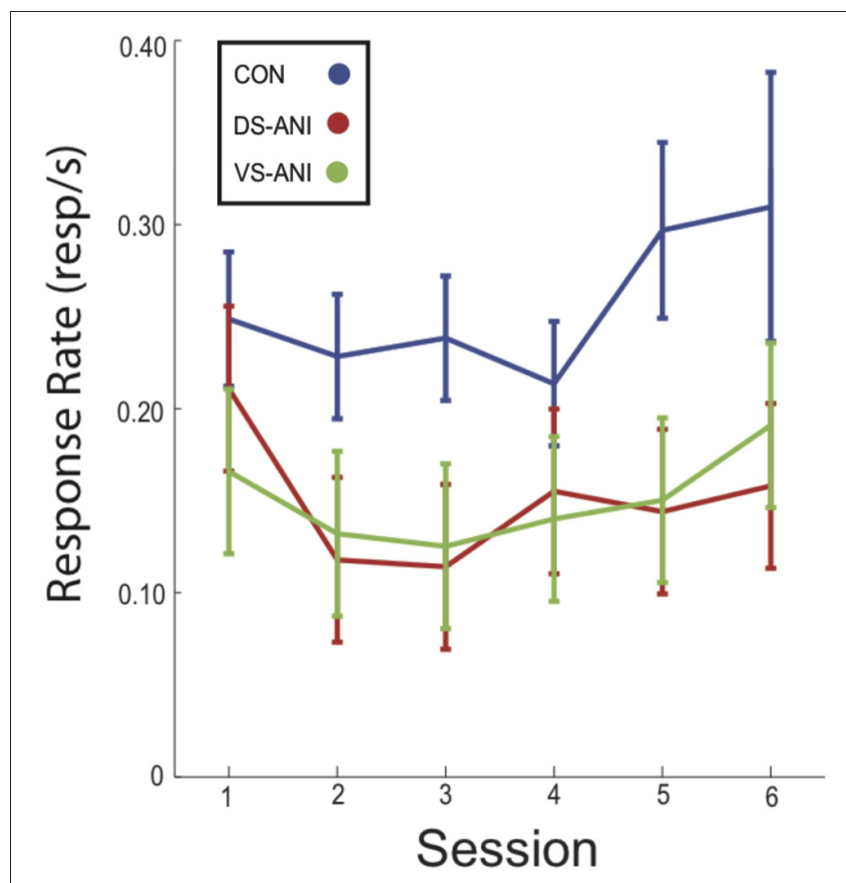

FIGURE 3 | Mean (土 SEM) response rate (responses/s) during probe trials across each of the six ANI treatment sessions for CON (blue), DS-ANI (red), and VS-ANI (green) treatment groups in Experiment 1. $\mathrm{ANI}=$ anisomycin; $\mathrm{CON}=$ control; $\mathrm{DS}=$ dorsal striatum. by the same degree relative to the CON treatment groups, the effects of ANI administration on the "Start" and "Stop" times for the DS-ANI and VS-ANI treatment groups were significantly different from each other as reported above.

\section{EXPERIMENT 2: ANISOMYCIN INFUSION INTO THE DORSAL STRIATUM IMPAIRS THE ACOUISITION OF THE "START" RESPONSE IN REFERENCE TO A SECOND TEMPORAL CRITERION}

In the present experiment, normal functioning was disrupted by ANI infusion into the DS while a group of rats was transitioned from a previously acquired $20 \mathrm{~s}$ temporal criterion to a new $50 \mathrm{~s}$ criterion. The effect of ANI on the "Start" response was evaluated during the acquisition of a second temporal criterion rather than the initial temporal criterion in order to avoid non-specific disruption of behavior due to failure to consolidate the association of the lever press with food reinforcement as opposed to failure to establish a decision threshold associated with a specific temporal criterion. Investigation of the effects of striatal disruption (including inhibition of protein synthesis) on the acquisition of a second "Start" threshold provides the subject with the option of maintaining the original "Start" threshold in the absence of the ability to acquire a new "Start" threshold, thus providing a more specific test of decision thresholds as opposed to simple instrumental associations (see Meck et al., 1984b; Balci et al., 2009).

Nineteen rats were first trained on a $20 \mathrm{~s}$ PI procedure (see Methods) and were then divided into two groups, which differed with respect to whether ANI (DS-ANI, $n=10$ ) or vehicle (DSCON, $n=9$ ) would be microinjected through bilateral cannulae placed into the DS. Within a session, $50 \%$ of the trials were FI trials. The remaining $50 \%$ of the trials were unreinforced probe trials during which the houselight stayed on for at least $60 \mathrm{~s}$ and no lever presses were reinforced (see Figure 1A and Methods section).

The baseline peak functions corresponding to probe trials obtained from the final two $20 \mathrm{~s}$ PI training sessions before ANI treatment are illustrated in Figure 4A. The peak functions are normalized with respect to the time-bin with the highest response rate (peak rate) in order to determine the shape of the temporal gradient and its centering around the target duration (peak time). Peak time and peak rate have been shown to be independent measures of performance with the former reflecting motivational factors and the later reflecting timing factors (Roberts, 1993; Cheng and Meck, 2007). "Start" times obtained from the single-trials analysis conducted across each of the PI $20 \mathrm{~s}$ baseline sessions are depicted in Figure 4D (left panel). A TwoWay ANOVA with Treatment and Session as factors indicated non-significant effects of Treatment $\left(F_{1,31}=0.15, p>0.05\right)$ and Session $\left(F_{1,31}=0.003, p>0.05\right)$, as well as a non-significant interaction between these two factors $\left(F_{1,31}=0.02, p>0.05\right)$ during the initial training phase.

Each treatment group was then transitioned to a $50 \mathrm{~s}$ PI training protocol and rats were microinjected with ANI or CON prior to the first 10 test sessions. Figure $4 \mathrm{~B}$ represents the mean peak functions obtained from Sessions 7-8 of ANI treatment while Figure 4D (center panel) illustrates the "Start" times obtained during each session of this transition phase as well as the PI $50 \mathrm{~s}$ baseline sessions (right panel). A Two-Way ANOVA conducted 


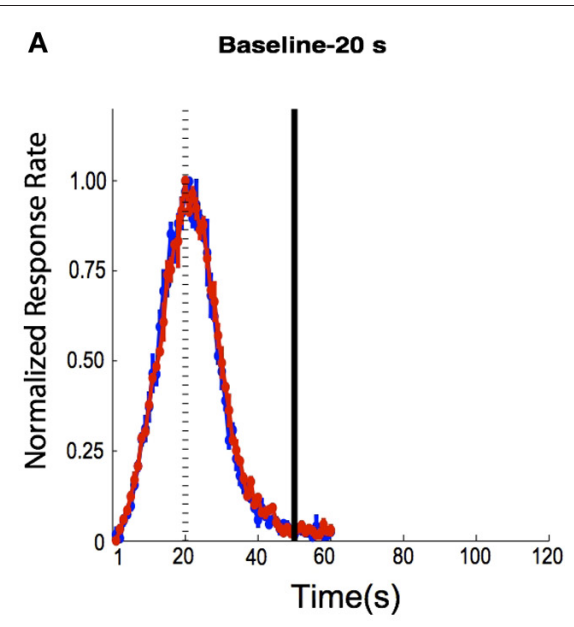

D

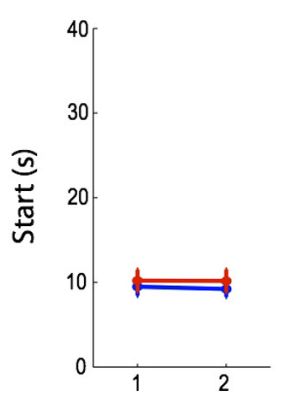

B

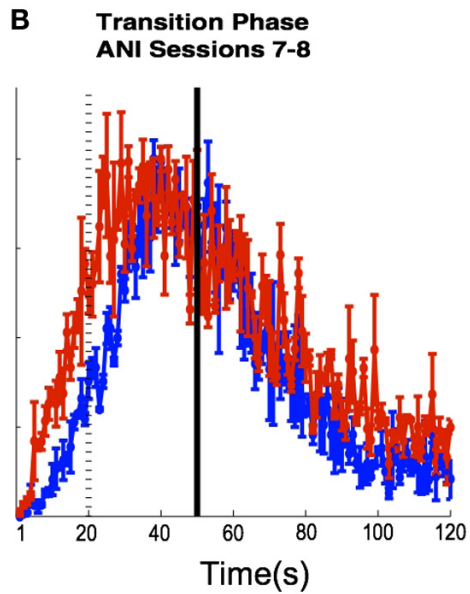

Baseline-50 s
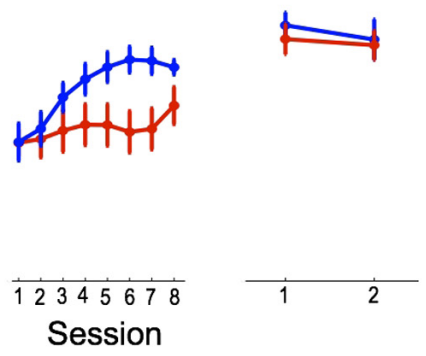

FIGURE 4 | (A) Baseline 20 s peak-interval (PI) functions for rats in the DS-CON (blue) and DS-ANI (red) treatment groups as a function of the last two sessions of $20 \mathrm{~s} \mathrm{Pl}$ training prior to the transition to $50 \mathrm{~s} \mathrm{PI}$ training. (B) Peak functions for each treatment group during Sessions 7-8 following the transition from $20 \mathrm{~s} \mathrm{PI} \rightarrow 50 \mathrm{~s} \mathrm{Pl}$ training. (C) Baseline $50 \mathrm{~s} \mathrm{PI}$

functions for both treatment groups averaged across two sessions three weeks after the ANI treatment ended. (D) "Start" times (s) for responding during the three specified phases of PI training for DS-CON and DS-ANI

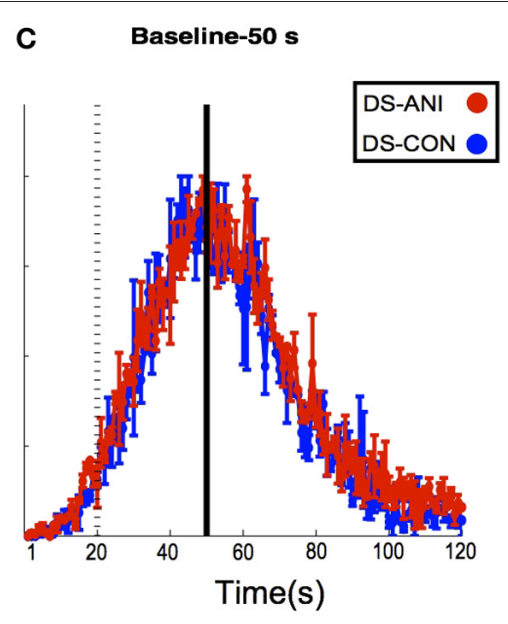

E Baseline-20 s

Transition Phase

Baseline-50 s

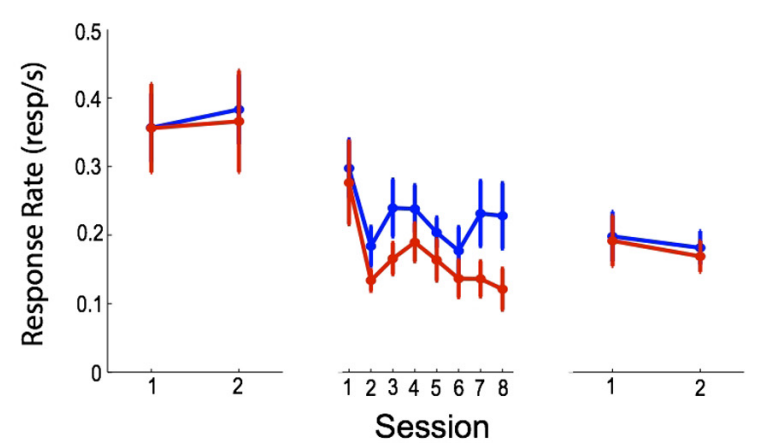

treatment groups. The Baseline 20 s PI and Baseline 50 s PI "Start" times during each session correspond to the peak functions displayed in Figures $\mathbf{2 A}, \mathbf{C}$. During the transition phase, individual data were smoothed across 10 sessions of microinjections using a running median with a 3-session window. (E) Mean ( \pm SEM) response rate (responses/s) on probe trials during the three specified phases of the experiment for the DS-CON and DS-ANI groups. ANI = anisomycin; $\mathrm{CON}=$ control; DS = dorsal striatum. on the $20 \mathrm{~s} \rightarrow 50 \mathrm{~s}$ transition phase data revealed significant effects on "Start" times with respect to Treatment and Session, $\left(F_{1,17}=4.47, p<0.05\right)$ and $\left(F_{7,119}=7.14, p<0.0001\right)$, respectively. In addition, a significant Treatment $\times$ Session interaction was observed, $\left(F_{7,119}=2.91, p<0.01\right)$. The mean response rates on probe trials during the three specified phases of the experiment for the DS-CON and DS-ANI treatment groups are illustrated in Figure 4E. A Two-Way ANOVA was conducted on each of these phases (Baseline-20s, Transition Phase, and Baseline-50 s). During the Transition Phase, a significant effect of Session was observed $\left(F_{7,119}=5.46, p<0.0001\right)$, but nonsignificant effects of Treatment $\left(F_{1,17}=2.60, p>0.05\right)$ as well as the Session $\times$ Treatment interaction $\left(F_{7,119}=0.69, p>0.05\right)$. In addition, there were no reliable effects of Session or Treatment on response rates during either of the $20 \mathrm{~s}$ or $50 \mathrm{~s}$ Baseline phases, p's $>0.05$.

Following the completion of ANI or vehicle administration $(\mathrm{CON})$, each treatment group continued to be trained on the
$50 \mathrm{~s}$ PI procedure, but with microinjections discontinued. While ANI administration significantly impaired the acquisition of the "Start" response across the 10 treatment sessions, there did not appear to be any long-lasting functional damage to the DS with respect to the temporal control of behavior. Figure 4C shows the mean peak functions for each treatment group obtained approximately three weeks (post-ANI Sessions 21-22) following microinjections while Figure 4D (right panel) depicts the "Start" times during this Baseline-50 s phase. A Two-Way ANOVA with Treatment and Session as factors indicated non-significant effects of Treatment $\left(F_{1,32}=0.71, p>0.05\right)$, Session $\left(F_{1,32}=1.07, p>\right.$ $0.05)$, as well as the Treatment $\times$ Session interaction $\left(F_{1,32}=\right.$ $0.11, p>0.05)$.

Histological examination for rats bearing bilateral, indwelling cannulae aimed at the DS and VS verified accurate placements for all rats in the ANI and CON treatment groups at both anatomical locations. A summary of these results for Experiment 1 and 2 is provided in Figure 5 (panels A-C). 


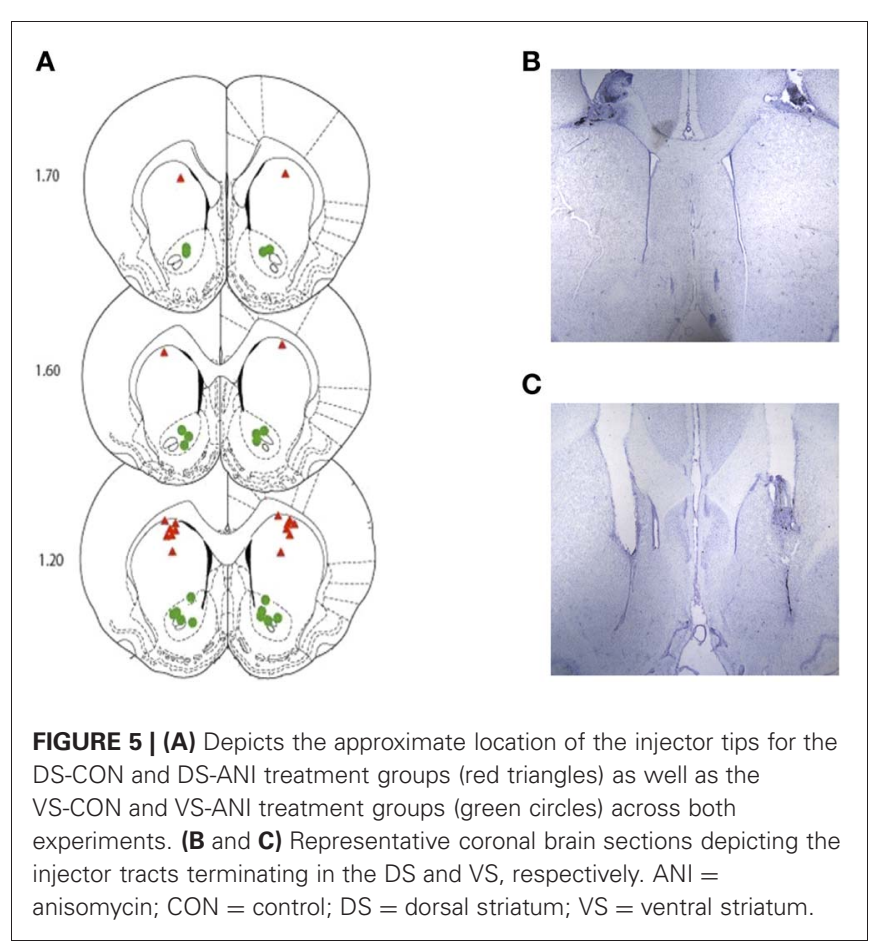

\section{DISCUSSION}

In this series of experiments we provide the first demonstrations that differential patterns of activity in the dorsal and VS are required for the types of decision-making used in the temporal control of response sequences. In particular, normal functioning of the DS is necessary for the acquisition of a timed "Start" response and similar activation in the VS, but not the DS, is required for the acquisition of a timed "Stop" response. Interestingly, during acquisition of the "Stop" response, the "Start" responses exhibited by the rats in the DS-ANI treatment group were sharper relative to the timing performance of the rats in the other treatment groups. This observation supports our finding in Experiment 2 that the DS is connected with the "Start" response. Therefore, ANI infusion into the DS maintained and/or increased the precision of the temporal estimate for the "Start" response while rats were acquiring the "Stop" response. The basis for this double dissociation might be grounded in the behavioral context that underlies PI training and the acquisition of a "Start" response. Indeed, this finding suggests that a decrease in the probability of reward relating to a predictive cue (i.e., houselight), which until this point in training had reliably signaled the expected time of reward delivery, brings about activational changes (possibly involving protein synthesis) in both the DS and VS.

In concert with mesolimbic dopaminergic input, the VS is believed to contribute to "behavioral switching," which reflects the reallocation of behavioral resources from current behavior(s) to subsequent one(s) in a flexible manner (Koob et al., 1978; Cools, 1980; Robbins and Brown, 1990; Redgrave et al., 1999). Indeed, the VS inhibit habitual responding in situations during which there is no reward or low stimulus control (Reading and Dunnett, 1991). Though interval timing is typically not studied within an associative framework (Kirkpatrick and Church, 1998), it is well-known that FI schedules can promote responding guided by "habitual" (S-R) associative content (Dickinson et al., 1983) and the transition to habitual responding can occasion changes within neurotransmitter systems that are directly related to interval timing (Choi et al., 2005; Faure et al., 2005; Yin and Knowlton, 2006; DeRusso et al., 2010). Moreover, it is often suggested that the VS contributes to goal-directed behavior by serving as an interface between limbic regions, which are thought to underlie affective (e.g., amygdalar) and contextual (e.g., hippocampal) processing, and provides a structural nexus whereby motivational information can gain access to predictive stimuli (Cardinal et al., 2002; Kelley, 2004; van der Meer et al., 2010). With this in mind, the VS might contribute to the acquisition of the "Stop" response by integrating updated, behavioraly-relevant information with output from a neural timing mechanism, which provides a signal for when the expected time of reward has passed. Downstream motor structures could then be triggered to coordinate the termination of an ongoing response sequence (see Roesch et al., 2009). In this sense, the "Stop" response in the PI timing procedure corresponds to the "giving-up time" in foraging situations where a subject has to decide when to leave a patch. "Giving-up times" have been shown to be more sensitive to the distribution of reinforcement times and magnitudes than the decision of when to enter a patch-which have been related to the differential control of "Start" and "Stop" responses in the PI timing procedure (Brunner et al., 1992, 1996, 1997; Taylor et al., 2007).

Conversely, activational changes (possibly involving protein synthesis) in the DS appear to contribute to the shaping of the "Start" response, which determines when the onset of the "high state" occurs. Some researchers have proposed that the DS plays an important role in the initiation of response sequences (Carli et al., 1985; Robbins and Brown, 1990; Graybiel, 1998; Bailey and Mair, 2006), but precise role(s) of the basal ganglia in kinematics and habits remain controversial (Graybiel, 2008; Desmurget and Turner, 2010; Turner and Desmurget, 2010). In Experiment 2, ANI infusion into the DS impaired the rightward transition in the "Start" response that normally takes place after switching from a $20 \mathrm{~s}$ to a $50 \mathrm{~s}$ temporal criterion. However, from our results, it is unclear how the acquisition of a "Start" response is mediated by activational changes in the DS. Indeed, in both Experiment 1 and 2 , the differences observed with respect to the "Start" response in the DS-ANI group emerged (1) after an initial "Start" response was well-learned (i.e., following extensive training with one target duration) and (2) under conditions where uncertainty with regard to the expected time of reward delivery is present. This suggests that activational changes (including protein synthesis) in the DS can come on-line during transitional conditions in which the temporal contingencies that guided the "Start" response over an extended period need to be updated. Similarly, for example, the DS neuronal population changes on many dimensions as an animal learns to respond optimally on a T-maze. In this case, neurons gradually transition to preferably encode the beginning and end of the acquired response sequence in the T-maze. However, the specificity of the response profile for the beginning and end abruptly decreases during transitional conditions such as those reported in Barnes et al. (2005). In our experiment, ANI infusion 
into the DS may resist a "reorganization" that takes place when unrewarded probe trials are first introduced, which is brought about by competing stimuli that change when a response sequence is initiated.

Unlike Experiment 1, the target duration was changed in the Experiment 2. Therefore, it is possible that striatal activation (possibly including protein synthesis) is required to encode a memory of the new target duration, making the effect on the "Start" response threshold ancillary. However, there is reason to suspect that this isn't the case. The change in the target duration was detected during the first session because the "Start" response from both DS and CON groups jumped to a later time even after ANI infusion. In fact, previous work has shown that memories for new target durations can be encoded after relatively few trials and response thresholds are shaped thereafter Meck et al., 1984b; Meck, 1988; Drew et al., 2004; Balsam and Gallistel, 2009. Given our findings from Experiment 1, it seems that activational changes in the DS are required to modulate the "Start" response. The target duration may be encoded either outside the DS or in a more specific DS sub-region than we targeted with the AIN infusions (Meck, 2006b; Yin and Knowlton, 2006). It's also worth considering that protein synthesis may not be required to encode the memory for a target duration, regardless of where it is stored (Routtenberg, 2008).

The dynamics of behavioral transitions in rodents, birds, and humans have demonstrated both abrupt and gradual transitions in the adjustment to changes in the time of reinforcement in the PI timing procedure (Meck et al., 1984a,b; Lejeune et al., 1997; Rodríguez-Gironés and Kacelnik, 1999; Simen et al., 2011). Whether or not these transitions initially involve an abrupt transition to an "intermediate" state appears to depend upon whether the adjustment is from a lower to a higher target duration or vice versa, the ratio of the times of reinforcement, the ratio of FI trials to unreinforced probe trials, and the subject's previous experience with such transitions (Meck et al., 1984a,b; Lejeune et al., 1997). Under the conditions used in the current experiment, it is expected that when rats are transitioned from a $20 \mathrm{~s}$ PI procedure to a $50 \mathrm{~s}$ PI procedure using a ratio of $50 \%$ FI trials to $50 \%$ unreinforced probe trials they will initially exhibit a relatively abrupt transition of their "Start" times from those appropriate to the $20 \mathrm{~s}$ target duration to an intermediate value near the geometric mean of the $20 \mathrm{~s}$ and $50 \mathrm{~s}$ target durations. This step is thought to result from the subject comparing the remembered rate of reinforcement under the $20 \mathrm{~s}$ condition to the experienced rate of reinforcement under the new $50 \mathrm{~s}$ condition and not necessarily the rapid acquisition of a new target duration - which would be expected to occur in a more gradual manner. Such continuous updating of the subjective probabilities of reinforcement operates in parallel to the adjustment of "Start" and "Stop" response thresholds centered around specific times of reinforcement-much like the processing of variable-interval vs. fixed-interval schedules of reinforcement (Hinton and Meck, 1997a,b; Rodríguez-Gironés and Kacelnik, 1999). Consequently, in the current experiment it might be expected that when rats are transitioned from a $20 \mathrm{~s}$ to a $50 \mathrm{~s}$ temporal criterion the initial adjustment of the "Start" response to an intermediate state would be unimpaired by ANI administration, whereas the second step involving the acquisition of a "Start" response appropriate to the $50 \mathrm{~s}$ target duration would be impaired as this requires the acquisition of a new temporal criterion and associated response thresholds as opposed to the monitoring of changes in the overall rates of reinforcement and the adjustment of previously acquired response thresholds (Lejeune et al., 1997). Moreover, the abrupt jump to an intermediate duration isn't influenced by hippocampal lesions and may be indicative of subjects using their old "Stop" threshold as a temporary "Start" threshold during this transition period (Meck et al., 1984a,b; Meck, 1988; MacDonald et al., 2007, 2009, 2011; Yin and Troger, 2011).

Our results also show that VS can contribute importantly to interval timing during learning. On the surface, it seems plausible that the "Stop" response ought to be mediated by behavioral and neural processes similar to those that operate during extinction (Myers and Davis, 2002; Lattal et al., 2006). Indeed, like extinction the acquisition of the "Stop" response appears to reflect new learning that is independent of the "Start" response. Moreover, several experiments have shown that VS lesions can lead to persistent responding during extinction of other operant tasks (Annett et al., 1989; Reading and Dunnett, 1991; Reading et al., 1991). However, in the case of the PI timing procedure, the extinction is partial. Reward is obtained on a random proportion (e.g., 50\%) of FI trials and "extinction" of responding during the unreinforced probe trials exhibits a temporal gradient indicating that it is strongly guided by the memory of the target duration (see Kaiser, 2008).

Regardless of its relationship to extinction, the emergence of the "Stop" response might reflect learning that there is little value to sustaining a high response rate once the target duration has passed. In this regard, the VS may be involved in the "invigoration" of behavior (Cardinal et al., 2002; Robbins and Everitt, 2007), and may do so by dynamically tracking the value of the predictive signal O'Doherty et al., 2004; Atallah et al., 2007; Niv, 2007. Therefore, in order to terminate the ongoing response sequence, activational changes (possibly including protein synthesis) in the VS are required for the integration of time-related information with the "Stop" response. This allows the animal to reallocate its behavioral resources from current behavior(s) to subsequent one(s) in a flexible manner (Koob et al., 1978; Cools, 1980; Robbins and Brown, 1990).

The basal ganglia are known to receive rich and diffuse input from many brain regions, especially the midbrain dopaminergic area, which is sensitive to both the expected time of reward and changes in reward probability-two conditions that characterize each of our experimental contexts (Hollerman and Schultz, 1998; Fiorillo et al., 2003). Our results suggest a regional dissociation between how these different types of information might be integrated to influence behavior. Moreover, they are supported by a study that confirmed a double dissociation with respect to the role of the DS and VS on reconsolidation during the instrumental learning of a lever press (Hernandez et al., 2002). In this case, ANI impeded the acquisition of lever pressing following post-session administration into the accumbens core of the VS, the brain area primarily targeted in our experiments. In contrast, post-session ANI injections into the DS facilitated the acquisition of an instrumental response, which we speculate might arise from a decrease 
in the effect of task-irrelevant stimuli impinging on the DS. An intriguing possibility is that these two striatal regions might function as a competitive network early in learning, which ultimately promotes optimal behavioral allocation (Hernandez et al., 2002; MacDonald and Meck, 2004, 2005; Kimchi and Laubach, 2009; Kimchi et al., 2009; Yin et al., 2009; Smith et al., 2010). In the present experiment, ANI was microinjected before the sessions began so we can't distinguish whether the effects we observed are targeting the memory consolidation, or a reconsolidation process. However, our experiments support and extend earlier findings by implicating a dissociable role for the DS and VS regarding when a response sequence should be initiated and terminated on the basis of a real-time temporal expectation.

The striatal beat-frequency (SBF) model of interval timing ascribes a mechanism for detecting event durations to medium spiny neurons within the DS (MacDonald and Meck, 2004; Matell and Meck, 2004; Buhusi and Meck, 2005; Lustig et al., 2005; Coull et al., 2011; Oprisan and Buhusi, 2011; Allman and Meck, 2012). These striatal neurons have a set of functional properties that place them in an ideal position to detect behaviorally relevant patterns of afferent cortical input (Beiser and Houk, 1998). Briefly, the SBF model posits that medium spiny neurons in the DS become entrained to fire in response to oscillating, coincident cortical inputs that become active at a particular duration. This timing model is particularly useful insofar as the striatal neurons modeled using the SBF framework behave as they do using multiunit electrical recordings during interval-timing procedures (Matell et al., 2003; Matell and Meck, 2004). However, in this model, there is relatively less focus on the role of the VS in interval timing primarily because timing behavior at steady state appears more influenced by manipulations targeting the DS rather than the VS (Gibbon et al., 1997; Meck, 2006b; Kurti and Matell, 2011). Moreover, our results suggest that the VS might contribute importantly to the acquisition of timing behavior. In this way, DS neurons would be responsible for encoding event durations, but feedback from the VS and other parts of the basal ganglia and/or limbic system are used to modulate the output of striatal spiny neurons in the DS (Berke et al., 2004; MacDonald and Meck, 2004, 2005; O'Doherty et al., 2004; Shea-Brown et al., 2006; Atallah et al., 2010; Gage et al., 2010; Coull et al., 2011).

\section{SUMMARY}

Despite numerous claims that the inhibition of protein synthesis following ANI administration directly interferes with memory formation (Abel and Lattal, 2001; Alberini, 2008; Kwapis et al., 2011; Okamoto et al., 2011), there are compelling reasons to be more cautious in this interpretation. Gold and colleagues, for example, have argued that ANI induces temporary amnesia rather than inhibition of memory formation per se (Canal and Gold, 2007; Canal et al., 2007; Gold, 2008; Qi and Gold, 2009; Sadowski et al., 2011). Such amnesia might result, in part, from the disruption of neurotransmitter systems, including the increased release of norepinephrine, dopamine, and serotonin (Canal et al., 2007). When these unintended "side effects" were blocked, leaving the inhibition of protein synthesis largely unchanged, no reliable memory impairment was observed (Canal et al., 2007; Qi and Gold, 2009; Sadowski et al., 2011). As a consequence, some investigators have been skeptical of the role of protein synthesis in memory formation (for review see Alberini, 2008; Gold, 2008; Rudy, 2008; Rudy and Sutherland, 2008). Moreover, even when ANI is administered post-session and, therefore, thought to only affect processes involved in memory consolidation and not behavioral performance during the task, there is the potential to impair instrumental learning by drug-induced devaluation of the reward (e.g., food or sucrose pellet) which can affect behavioral performance in subsequent sessions as demonstrated by Jonkman and Everitt (2009).

In the current study, ANI infusions were given prior to the start of a training session in order to maximize the chances of affecting learning and memory consolidation that would be expected to occur within the $2 \mathrm{~h}$ session. As a consequence, all of the concerns expressed above concerning performance variables are valid. The dissociation of timing performance for "Start" and "Stop" response thresholds as a function of ANI infusion into either the dorsal or VS suggests selective effects depending upon the type of response and brain region, as well as the degree of behavioral training and whether short-term or long-term memory processes are involved. In Experiment 2 for example, during the transition from a $20 \mathrm{~s}$ to a $50 \mathrm{~s}$ target duration, rats initially used a criterion that was intermediate between the two times of reinforcement. The determination of this intermediate target duration (which was never reinforced) presumably requires some sort of short-term memory process to be engaged. The observation that these early transitional processes were unaffected by ANI infusion, but that the more gradual acquisition of the "Start" response for the new $50 \mathrm{~s}$ target duration was selectively impaired by ANI infusion into the DS is consistent with a "protein synthesis" argument, i.e., that only those mechanisms responsible for the formation of long-term memories/response thresholds associated with the $50 \mathrm{~s}$ target duration were impacted by ANI infusion.

Taken together, our results point to a regional dissociation between how temporal information is used to guide separate components of a response sequence. Both the "Start" and "Stop" response thresholds serve as temporal boundaries that define transitions between two measurably different behavioral "states" occur. Clearly, there are many more questions as to why these transitions are different in the first place and require different brain structures. For example, it might be the case that the response topography of the state from which the transition leaves, or to which the transition leads represents an important factor. For some types of responses (e.g., discrete or sustained), response duration and the probability of response initiation can be differentiated by drugs that target D1 and D2 receptors, respectively (Gooch et al., 2007; Choi et al., 2005). Whatever the case, an intriguing possibility is that the dorsal and ventral striatal regions might function as a competitive network designed to respond to temporal information during the early stages of learning. The tracking of temporal regularities in the environment ultimately enhances adaptive behavior and may eventually lead to habit formation (Hernandez et al., 2002; MacDonald and Meck, 2004, 2005; Cheng et al., 2007a,c; Kimchi and Laubach, 2009; Kimchi et al., 2009; Yin et al., 2009; Smith et al., 2010). As such, most neurophysiological models of interval timing assume that target durations are encoded into a region's neuronal 
network in part through the modification of synaptic weights (Coull et al., 2011; Oprisan and Buhusi, 2011; Allman and Meck, 2012). In this way, it is important to explicitly test how and where these long-term modifications might be carried out at the cellular level by making use of what we know in other learning settings. In this regard, while there remains much to explore, these experiments using ANI infusions are among the first to isolate the roles of the dorsal and VS in temporal processing (see Meck, 2006b).

\section{REFERENCES}

Abel, T., and Lattal, K. M. (2001). Molecular mechanisms of memory acquisition, consolidation and retrieval. Curr. Opin. Neurobiol. 11, 180-187.

Agostino, P. V., Golombek, D. A., and Meck, W. H. (2011). Unwinding the molecular basis of interval and circadian timing. Front. Integr. Neurosci. 5:64. doi: 10.3389/fnint. 2011.00064

Alberini, C. M. (2008). The role of protein synthesis during the labile phases of memory: revisiting the skepticism. Neurobiol. Learn. Mem. 89, 234-246.

Aldridge, J. W., and Berridge, K. C. (1998). Coding of serial order by neostriatal neurons: a "natural action" approach to movement sequence. J. Neurosci. 18, 2777-2787.

Allman, M. J., and Meck, W. H. (2012). Pathophysiological distortions in time perception and timed performance. Brain 135, 656-677.

Annett, L. E., McGregor, A., and Robbins, T. W. (1989). The effects of ibotenic acid lesions of the nucleus accumbens on spatial learning and extinction in the rat. Behav. Brain Res. 31, 231-242.

Atallah, H. E., Lopez-Paniagua, D., Rudy, J. W., and O'Reilly, R. C. (2007). Separate neural substrates for skill learning and performance in the ventral and dorsal striatum. Nat. Neurosci. 10, 126-131.

Atallah, H. E., Lopez-Paniagua, D., Rudy, J. W., and O'Reilly, R. C. (2010). Separate neural substrates for skill learning and performance in the ventral and dorsal striatum. Nat. Neurosci. 10, 126-131.

Bailey, K. R., and Mair, R. G. (2006). The role of striatum in initiation and execution of learned action sequences in rats. J. Neurosci. 26, 1016-1025.

Balci, F., Gallistel, C. R., Allen, B. D., Frank, K. M., Gibson, J. M., and Brunner, D. (2009). Acquisition of peak responding: what is learned? Behav. Process. 80, 67-75.

Balsam, P. D., and Gallistel, C. R. (2009). Temporal maps and informativeness in associative learning. Trends Neurosci. 32, 73-78.
Barnes, T. D., Kubota, Y., Hu, D., Jin, D. Z., and Graybiel, A. M. (2005). Activity of striatal neurons reflects dynamic encoding and recoding of 1158-1161.

Bateson, M. (2003). "Interval timing and optimal foraging," in Functional and Neural Mechanisms of Interval Timing, ed W. H. Meck (Boca-Raton, FL: CRC Press), 113-141.

Beiser, D. G., and Houk, J. C. (1998). Model of cortical-basal ganglionic processing: encoding the serial order of sensory events. $J$. Neurophysiol. 79, 3168-3188.

Berke, J. D., Okatan, M., Skurski, J., and Eichenbaum, H. B. (2004). Oscillatory entrainment of striatal neurons in freely moving rats. Neuron 43, 883-896.

Bromberg-Martin, E. S., Matsumoto, M., and Hikosaka, O. (2010). Distinct tonic and phasic anticipatory activity in lateral habenula and dopamine neurons. Neuron 67, 144-155.

Brunner, D., Fairhurst, S., Stolovitzky, G., and Gibbon, J. (1997). Mnemonics for variability: remembering food delay. J. Exp. Psychol. Anim. Behav. Process. 23, 68-83.

Brunner, D., Kacelnik, A., and Gibbon, J. (1992). Optimal foraging and timing processes in the starling, Sturnus vulgaris: effect of intercapture interval. Anim. Behav. 44, 597-613.

Brunner, D., Kacelnik, A., and Gibbon, J. (1996). Memory for interreinforcement interval variability and patch departure decisions in the starling, Sturnus vulgaris. Anim. Behav. 51, 1025-1045.

Bueti, D. (2011). The sensory representation of time. Front. Integr. Neurosci. 5:34. doi: 10.3389/fnint. 2011.00034

Buhusi, C. V., Aziz, D., Winslow, D., Carter, R. E., Swearington, J. E., and Buhusi, M. C. (2009). Interval timing accuracy and scalar timing in c57BL/6 mice. Behav. Neurosci. 123, 1102-1113.

Buhusi, C. V., and Meck, W. H. (2000). Timing for the absence of a stimulus: the gap paradigm reversed. procedural memories. Nature 437,

\section{ACKNOWLEDGMENTS}

We would like to thank Elizabeth Clore, Erin Crawford, Antonia Laino, and Henry Yin for their assistance and support during the course of this project. This work was supported, in part, by an award from the James McKeen Cattell Fund (Warren H. Meck). Portion of this work have been previously reported at the annual meeting of the Society for Neuroscience (MacDonald et al., 2005, 2006).

J. Exp. Psychol. Anim. Behav. Process. 26, 305-322.

Buhusi, C. V., and Meck, W. H. (2002) Differential effects of methamphetamine and haloperidol on the control of an internal clock. Behav. Neurosci. 116, 291-297.

Buhusi, C. V., and Meck, W. H. (2005). What makes us tick? Functional and neural mechanisms of interval timing. Nat. Rev. Neurosci. 6, 755-765.

Buhusi, C. V., and Meck, W. H. (2006). Interval timing with gaps and distracters: evaluation of the ambiguity, switch, and time-sharing hypotheses. J. Exp. Psychol. Anim. Behav. Process. 32, 329-338.

Buhusi, C. V., and Meck, W. H. (2009a). Relative time sharing: new findings and an extension of the resource allocation model of temporal processing. Philos. Trans. R. Soc. Lond. B Biol. Sci. 364, 1875-1885.

Buhusi, C. V., and Meck, W. H. (2009b). Relativity theory and time perception: single or multiple clocks? PLoS One 4:e6268. doi: 10.1371/journal. pone.0006268

Buhusi, C. V., Sasaki, A., and Meck, W. H. (2002). Temporal integration as a function of signal/gap intensity in rats (Rattus norvegicus) and pigeons (Columba livia). J. Comp. Psychol. 116, 381-390.

Canal, C. E., Chang, Q., and Gold, P. E. (2007). Amnesia produced by altered release of neurotransmitters after intraamygdala injections of a protein synthesis inhibitor. Proc. Natl. Acad. Sci. U.S.A. 104, 12500-12505.

Canal, C. E., and Gold, P. E. (2007). Different temporal profiles of amnesia after intra-hippocampus and intra-amygdala infusions of anisomysin. Behav. Neurosci. 121, 732-741.

Cardinal, R. N., Parkinson, J. A., Hall, J., and Everitt, B. J. (2002). Emotion and motivation: the role of the amygdala, ventral striatum, and prefrontal cortex. Neurosci. Biobehav. Rev. 26, 321-352.

Carli, M., Evenden, J. L., and Robbins, T. W. (1985). Depletion of unilateral striatal dopamine impairs initiation of contralateral actions and not sensory attention. Nature 313, 679-682.

Castellucci, V. F., Blumenfeld, H., Goelet, P., and Kandel, E. R. (1989). Inhibitor of protein synthesis blocks longterm behavioral sensitization in the isolated gill-withdrawal reflex of Aplysia. J. Neurobiol. 20, 1-9.

Choi, W. Y., Balsam, P. D., and Horvitz, J. C. (2005). Extended habit training reduces dopamine mediation of appetitive response expression. J. Neurosci. 25, 6729-6733.

Cheng, R. K., Ali, Y. M., and Meck, W. H. (2007a). Ketamine "unlocks" the reduced clock-speed effect of cocaine following extended training: evidence for dopamineglutamate interactions in timing and time perception. Neurobiol. Learn. Mem. 88, 149-159.

Cheng, R. K., Etchegaray, M., and Meck, W. H. (2007b). Impairments in timing, temporal memory, and reversal learning linked to neurotoxic regimens of methamphetamine intoxication. Brain Res. 1186, 255-266.

Cheng, R. K., Hakak, O. L., and Meck, W. H. (2007c). Habit formation and the loss of control of an internal clock: inverse relationship between the level of baseline training and the clock-speed enhancing effects of methamphetamine. Psychopharmacology 193, 351-362.

Cheng, R. K., Jesuthasan, S., and Penney, T. B. (2011). Time for zebrafish. Front. Integr. Neurosci. 5:40. doi: 10.3389/fnint.2011.00040

Cheng, R. K., MacDonald, C. J., and Meck, W. H. (2006). Differential effects of cocaine and ketamine on time estimation: implications for neurobiological models of interval timing. Pharmacol. Biochem. Behav. 85, 114-122.

Cheng, R. K., and Meck, W. H. (2007). Prenatal choline supplementation increases sensitivity to time by reducing non-scalar sources of variance in adult temporal processing. Brain Res. 1186, 242-254.

Church, R. M., Meck, W. H., and Gibbon, J. (1994). Application of scalar timing theory to individual trials. J. Exp. Psychol. Anim. Behav. Process. 20, 135-155. 
Church, R. M., Miller, K. D., Meck, W. H., and Gibbon, J. (1991). Symmetrical and asymmetrical sources of variance in temporal generalization. Anim. Learn. Behav. 19, 207-214

Cools, A. R. (1980). Role of the neostriatal dopaminergic activity in sequencing and selecting behavioural strategies: facilitation of processes involved in selecting the best strategy in a stressful situation. Behav. Brain Res. 1, 361-378.

Coull, J. T., Cheng, R. K., and Meck, W. H. (2011). Neuroanatomical and neurochemical substrates of timing. Neuropsychopharmacology 36, $3-25$.

Coull, J. T., Vidal, F., Nazarian, B., and Macar, F. (2004). Functional anatomy of the attentional modulation of time estimation. Science 303, 1506-1508.

Cromwell, H. C., and Berridge, K. C. (1996). Implementation of action sequences by a neostriatal site: a lesion mapping study of grooming syntax. J. Neurosci. 16, 3444-3458.

Cui, X. (2011). Hyperbolic discounting emerges from the scalar property of interval timing. Front. Integr. Neurosci. 5:24. doi: 10.3389/fnint. 2011.00024

DeRusso, A. L., Fan, D., Gupta, J., Shelest, O., Costa, R. M., and Yin, H. H. (2010). Instrumental uncertainty as a determinant of behavior under interval schedules of reinforcement. Front. Integr. Neurosci. 4:17. doi: 10.3389/fnint.2010.00017

Desmurget, M., and Turner, R. S. (2010). Motor sequences and the basal ganglia: kinematics, not habits. J. Neurosci. 30, 7685-7690.

Dickinson, A., Nicholas, D. J., and Adams, C. D. (1983). The effect of the instrumental training contingency on susceptibility to reinforcer devaluation. Q. J. Exp. Psychol. B 35, 35-51.

Drew, M. R., Simpson, E. H., Kellendonk, C., Herzberg, W. G., Lipatova, O., Fairhurst, S., Kandel, E. R., Malapani, C., and Balsam, P. D. (2007). Transient overexpression of striatal D2 receptors impairs operant motivation and interval timing. J. Neurosci. 27, 7731-7739.

Drew, M. R., Yang, C., Ohyama, T., and Balsam, P. D. (2004). Temporal specificity of extinction in autoshaping. J. Exp. Psychol. Anim. Behav. Process. 30, 163-176.

Drew, M. R., Zupan, B., Cooke, A., Couvillon, P. A., and Balsam, P. D. (2005). Temporal control of conditioned responding in goldfish. $J$.
Exp. Psychol. Anim. Behav. Process. 31, 31-39.

Droit-Volet, S., and Meck, W. H. (2007). How emotions colour our perception of time. Trends Cogn. Sci. 11, 504-513.

Fantino, E., Dunn, R., and Meck, W. (1979). Percentage reinforcement and choice. J. Exp. Anal. Behav. 32, 335-340.

Faure, A., Haberland, U., Condé, F. and El Massioui, N. (2005). Lesion of the nigrostriatal dopamine system disrupts stimulus-response habit formation. J. Neurosci. 16, 2771-2780.

Fiorillo, C. D., Tobler, P. N., and Schultz, W. (2003). Discrete coding of reward probability and uncertainty by dopamine neurons. Science 299, 1898-1902.

Floresco, S. B., Ghods-Sharifi, S. Vexelman, C., and Magyar, O. (2006). Dissociable roles for the nucleus accumbens core and shell in regulating set shifting. J. Neurosci. 26, 2449-2457.

Forstmann, B. U., Dutilh, G., Brown, S., Neumann, J., von Cramon, D. Y., Ridderinkhof, K. R., and Wagenmakers, E. J. (2008). Striatum and pre-SMA facilitate decisionmaking under time pressure. Proc. Natl. Acad. Sci. U.S.A. 105, 17538-17542.

Freestone, D. M., and Church, R. M. (2010). The importance of the reinforcer as a time marker. Behav. Process. 84, 500-505.

Fujii, N., and Graybiel, A. M. (2005). Time-varying covariance of neural activities recorded in striatum and frontal cortex as monkeys perform sequential-saccade tasks. Proc. Natl. Acad. Sci. U.S.A. 102, 9032-9037.

Gage, G. J., Stoetzner, C. R., Wiltschko, A. B., and Berke, J. D. (2010). Selective activation of striatal fastspiking interneurons during choice execution. Neuron 67, 466-479.

Gallistel, C. R., and Gibbon, J. (2000). Time, rate, and conditioning. Psychol. Rev. 107, 289-344.

Gallistel, C. R., King, A., and McDonald, R. (2004). Sources of variability and systematic error in mouse timing behavior. J. Exp. Psychol. Anim. Behav. Process. 30, 3-16.

Gibbon, J., Church, R. M., and Meck, W. H. (1984). Scalar timing in temporal memory. Ann. N.Y. Acad. Sci. 423, 52-77.

Gibbon, J., Malapani, C., Dale, C. L., and Gallistel, C. R. (1997). Toward a neurobiology of temporal cognition: advances and challenges. Curr. Opin. Neurobiol. 7, 170-184.

Gold, P. E. (2008). Protein synthesis inhibition and memory: formation vs amnesia. Neurobiol. Learn. Mem. 89, 201-211.

Gooch, C. M., Wiener, M., Portugal, G. S., and Matell, M. S. (2007) Evidence for separate neural mechanisms for the timing of discrete and sustained responses. Brain Res. 1156, 139-151.

Graybiel, A. M. (1998). The basal ganglia and chunking of action repertoires. Neurobiol. Learn. Mem. 70, 119-136.

Graybiel, A. (2008). Habits, rituals, and the evaluative brain. Ann. Rev Neurosci. 31, 359-387.

$\mathrm{Gu}$, B. M., Yin, B., Cheng, R. K., and Meck, W. H. (2011) Quinpirole-induced sensitization to noisy/sparse periodic input: temporal synchronization as a component of obsessive-compulsive disorder. Neuroscience 179, 143-150.

Harrington, D. L., Boyd, L. A., Mayer, A. R., Sheltraw, D. M., Lee, R. R., Huang, M., and Rao, S. M (2004). Neural representation of interval encoding and decision making. Cogn. Brain Res. 21, 193-205.

Harrington, D. L., Castillo, G. N., Fong, C. H., and Reed, J. D. (2011a) Neural underpinnings of distortions in the experience of time across senses. Front. Integr. Neurosci. 5:32. doi: 10.3389/fnint.2011.00032

Harrington, D. L., Castillo, G. N., Greenberg, P. A., Song, D. D., Lessig, S., Lee, R. R., and Rao, S. M. (2011b). Neurobehavioral mechanisms of temporal processing deficits in Parkinson's disease. PLoS One 6:e17461. doi: 10.1371/journal. pone. 0017461

Hata, T. (2011). Glutamate - a forgotten target for interval timing. Front. Integr. Neurosci. 5:27. doi: 10.3389/ fnint.2011.00027

Hernandez, P. J., and Kelley, A E. (2004). Long-term memory for instrumental response does not undergo protein synthesisdependent reconsolidation upon retrieval. Learn. Mem. 11, 748-754.

Hernandez, P. J., Sadeghian, K., and Kelley, A. E. (2002). Early consolidation of instrumental learning requires protein synthesis in the nucleus accumbens. Nat. Neurosci. $5,1327-1331$

Hinton, S. C., and Meck, W. H (1997a). "How time flies: functional and neural mechanisms of interval timing," in Time and Behaviour: Psychological and Neurobiological Analyses, eds C. M. Bradshaw and E. Szabadi (New York, NY: Elsevier), 409-457.

Hinton, S. C., and Meck, W. H. (1997b). The “internal clocks" of circadian and interval timing. Endeavour 21, 82-87.

Hinton, S. C., and Meck, W. H. (2004). Frontal-striatal circuitry activated by human peak-interval timing in the supra-seconds range. Cogn. Brain Res. 21, 171-182.

Höhn, S., Dallérac, G., Faure, A., Urbach, Y., Nguyen, H. P., Riess, O., von Hörsten, S., Le Blanc, P. Desvignes, N., El Massioui, N. Brown, B. L., and Doyère, V. (2011). Behavioral and in vivo electrophysiological evidence for presymptomatic alteration of prefrontostriatal processing in the transgenic rat model for Huntington disease. J. Neurosci. 31, 8986-8997.

Hollerman, J. R., and Schultz, W. (1998). Dopamine neurons report an error in the temporal prediction of reward during learning. Nat Neurosci. 1, 304-309.

Jin, D. Z., Fujii, N., and Graybiel, A. M. (2009). Neural representation of time in cortico-basal ganglia circuits. Proc. Natl. Acad. Sci. U.S.A. 106, 19156-19161.

Jin, X., and Costa, R. M. (2010). Striatal-specific deletion of NMDA receptors disrupts the development of start/top activity and impairs sequence learning. Nature 466, 457-462.

Jones, C. L., Minati, L., Harrison, N. A., Ward, J., and Critchley, H. D. (2011). Under pressure: response urgency modulates striatal and insula activity during decisionmaking under risk. PLoS One 6: e20942. doi: 10.1371/journal.pone. 0020942

Jones, C. R. G., and Jahanshahi, M. (2011). Dopamine modulates striato-frontal functioning during temporal processing. Front. Integr. Neurosci. 5:70. doi: 10.3389/fnint. 2011.00070

Jonkman, A., and Everitt, B. J. (2009). Post-learning infusion of anisomycin into the anterior cingulate cortex impairs instrumental acquisition through an effect on reinforcer valuation. Learn. Mem. 16, 706-713.

Kaiser, D. H. (2008). The proportion of fixed interval trials to probe trials affects acquisition of the peak procedure fixed interval timing task. Behav. Process. 77, 100-108.

Kelley, A. E. (2004). Ventral striatal control of appetitive motivation: role in ingestive behavior and reward-related learning. Neurosci. Biobehav. Rev. 27, 765-776.

Kimchi, E. Y., and Laubach, M. (2009). The dorsomedial striatum reflects response bias during learning. J. Neurosci. 29, 14891-14902. 
Kimchi, E. Y., Torrefrossa, M. M., Taylor, J. R., and Laubach, M. (2009). Neuronal correlates of instrumental learning in the dorsal striatum. J. Neurophysiol. 102, 475-489.

Kirkpatrick, K., and Church, R. M. (1998). Are separate theories of conditioning and timing necessary? Behav. Process. 44, 163-182.

Koob, G. F., Riley, S. J., Smith, S. C., and Robbins, T. W. (1978). Effects of 6-hydroxydopamine lesions of the nucleus accumbens septi and olfactory tubercle on feeding, locomotor activity, and amphetamine anorexia in the rat. J. Comp. Physiol. Psychol. 92, 917-927.

Kotz, S. A. E., and Schwartze, M. (2011). Differential input of the supplementary motor area to a dedicated temporal processing network: functional and clinical implications. Front. Integr. Neurosci. 5:86. doi: 10.3389/fnint.2011.00086

Kurti, A. N., and Matell, M. S. (2011). Nucleus accumbens dopamine modulates response rate but not response timing in an interval timing task. Behav. Neurosci. 125, 215-225.

Kwapis, J. L., Jarome, T. J., Schiff, J. C., and Helmstetter, F. J. (2011). Memory consolidation in both trace and delay fear conditioning is disrupted by intra-amygdala infusion of the protein synthesis inhibitor anisomycin. Learn. Mem. 18, 728-732.

Lattal, K. M., Radulovic, J., and Lukowiak, K. (2006). Extinction: does it or doesn't it? The requirement of altered gene activity and new protein synthesis. Biol. Psychiatry 15, 344-351.

Lejeune, H., Ferrara, A., Simons, F., and Wearden, J. H. (1997). Adjusting to changes in the time of reinforcement: peak-interval transitions in rats. J. Exp. Psychol. Anim. Behav. Process. 23, 211-231.

Liao, R. M., and Cheng, R. K. (2005). Acute effects of $\mathrm{d}$-amphetamine on the differential reinforcement of low-rate (DRL) schedule behavior in the rat: comparison with selective dopamine receptor antagonists. Chin. J. Physiol. 48, 41-50.

Lustig, C., Matell, M. S., and Meck, W. H. (2005). Not "just" a coincidence: frontal-striatal synchronization in working memory and interval timing. Memory 13, 441-448.

Lustig, C., and Meck, W. H. (2001). Paying attention to time as one gets older. Psychol. Sci.12, 478-484.

Lustig, C., and Meck, W. H. (2005). Chronic treatment with haloperidol induces working memory deficits in feedback effects of interval timing. Brain Cogn. 58, 9-16.

Lustig, C., and Meck, W. H. (2011). Modality differences in timing and temporal memory throughout the lifespan. Brain Cogn. 77, 298-303.

MacDonald, C. J., Cheng, R. K., Laino, A. M., and Meck, W. H. (2005). Protein synthesis and the "sculpting" of a temporal criterion: competitive interactions between dorsal and ventral striatum for learning when to start and stop responding. Abstr. Soc. Neurosci. 635.08.

MacDonald, C. J., Cheng, R. K., Clore, E. L., and Meck, W. H. (2006). Learning when to "start" and "stop" an action sequence: dissociable roles for de novo protein synthesis in the dorsal and ventral striatum. Abstr. Soc. Neurosci. 572.17.

MacDonald, C. J., Cheng, R. K., Williams, C. L., and Meck, W. H. (2007). Combined organizational and activational effects of short and long photoperiods on spatial and temporal memory in rats. Behav. Process. 74, 226-233.

MacDonald, C. J., LePage, K. Q., Eden, U. T., and Eichenbaum, H. (2011). Hippocampal "time cells" bridge the gap in memory for discontiguous events. Neuron 71, 737-749.

MacDonald, C. J., and Meck, W. H. (2004). Systems-level integration of interval timing and reaction time. Neurosci. Biobehav. Rev. 28, 747-769.

MacDonald, C. J., and Meck, W. H. (2005). Differential effects of clozapine and haloperidol on interval timing in the supraseconds range. Psychopharmacology 182, 232-244.

MacDonald, C. J., and Meck, W. H. (2006). Interaction of raclopride and preparatory-interval effects on simple reaction-time performance. Behav. Brain Res. 175, 62-74.

MacDonald, C. J., Meck, W. H., Simon, S. A., and Nicolelis, M. A. L. (2009) Taste-guided decision differentially engage neuronal ensembles across gustatory cortices. J. Neurosci. 29, 11271-11282.

Maimon, G., and Assad, J. A. (2006). A cognitive signal for the proactive timing of action in macaque LIP. Nat. Neurosci. 9, 948-955.

Malapani, C., Rakitin, B., Meck, W. H., Deweer, B., Dubois, B., and Gibbon, J. (1998). Coupled temporal memories in Parkinson's disease: a dopamine-related dysfunction. J. Cogn. Neurosci. 10, 316-331.

Mansfield, E. L., Karayanidis, F. Jamadar, S., Heathcote, A., and Forstmann, B. U. (2011).
Adjustments of response threshold during task switching: a model-based functional magnetic resonance imaging study. $J$. Neurosci. 31, 14688-14692.

Matell, M. S., Bateson, M., and Meck, W. H. (2006). Single-trials analyses demonstrate that increases in clock speed contribute to the methamphetamine-induced horizontal shifts in peak-interval timing functions. Psychopharmacology 188, 201-212.

Matell, M. S., King, G. R., and Meck, W. H. (2004). Differential adjustment of interval timing by the chronic administation of intermittent or continuous cocaine. Behav. Neurosci. 118, 150-156.

Matell, M. S., and Meck, W. H. (2000). Neuropsychological mechanisms of interval timing behavior. Bioessays 22, 94-103.

Matell, M. S., and Meck, W. H. (2004). Cortico-striatal circuits and interval timing: coincidence-detection of oscillatory processes. Cogn. Brain Res. 21, 39-70.

Matell, M. S., Meck, W. H., and Nicolelis, M. A. L. (2003). Interval timing and the encoding of signal duration by ensembles of cortical and striatal neurons. Behav. Neurosci. 117, 760-773.

Matell, M. S., Shea-Brown, E., Gooch, C., Wilson, A. G., and Rinzel, J. (2011). A heterogeneous population code for elapsed time in rat medial agranular cortex. Behav. Neurosci. 125, 54-73.

Meck, W. H. (1983). Selective adjustment of the speed of internal clock and memory processes. J. Exp. Psychol. Anim. Behav. Process. 9, 171-201.

Meck, W. H. (1988). Hippocampa function is required for feedback control of an internal clock's criterion. Behav. Neurosci. 102, 54-60.

Meck, W. H. (1991). Modality-specific circadian rhythmicities influence mechanisms of attention and memory for interval timing. Learn. Motiv. 22, 153-179.

Meck, W. H. (1996). Neuropharmacology of timing and time perception. Cogn. Brain Res. 3, 227-242.

Meck, W. H. (2002). Choline uptake in the frontal cortex is proportional to the absolute error of a temporal memory translation constant in mature and aged rats. Learn. Motiv. 33, 88-104.

Meck, W. H. (2003). Functional and Neural Mechanisms of Interval Timing. Boca Raton, FL: CRC Press.

Meck, W. H. (2006a). Frontal cortex lesions eliminate the clock speed effect of dopaminergic drugs on interval timing. Brain Res. 1108 157-167.

Meck, W. H. (2006b). Neuroanatomical localization of an internal clock: a functional link between mesolimbic, nigrostriatal, and mesocortical dopaminergic systems. Brain Res. 1109, 93-107.

Meck, W. H. (2006c). Temporal memory in mature and aged rats is sensitive to choline acetyltransferase inhibition. Brain Res. 1108, 168-175.

Meck, W. H., and Benson, A. M. (2002). Dissecting the brain's internal clock: how frontal-striatal circuitry keeps time and shifts attention. Brain Cogn. 48, 195-211.

Meck, W. H., Cheng, R. K., MacDonald, C. J., Gainetdinov, R. R., Caron, M. G., and Çevik, M. Ö. (2012). Gene-dose dependent effects of methamphetamine on interval timing in dopamine-transporter knockout mice. Neuropharmacology 62, 1221-1229.

Meck, W. H., and Church, R. M. (1982). Abstraction of temporal attributes. J. Exp. Psychol. Anim. Behav. Process. 8, 226-243.

Meck, W. H., and Church, R. M. (1984). Simultaneous temporal processing. J. Exp. Psychol. Anim. Behav. Process. 10, 1-29.

Meck, W. H., Church, R. M., and Olton, D. S. (1984a). Hippocampus, time, and memory. Behav. Neurosci. 98, 3-22.

Meck, W. H., Komeily-Zadeh, F. N., and Church, R. M. (1984b). Twostep acquisition: modification of an internal clock's criterion. J. Exp. Psychol. Anim. Behav. Process. 10, 297-306.

Meck, W. H., and MacDonald, C. J. (2007). Amygdala inactivation reverses fear's ability to impair divided attention and make time stand still. Behav. Neurosci. 121, 707-720.

Meck, W. H., Penney, T. B., and Pouthas, V. (2008) Cortico-striatal representation of time in animals and humans. Curr. Opin. Neurobiol. 18, 145-152.

McClure, S. M., Laibson, D. I., Lowenstein, G., and Cohen, J. D. (2004). Separate neural systems value immediate and delayed monetary rewards. Science 306, 503-507.

Morris, R. G. M., Inglis, J., Ainge, J. A., Olverman, H. J., Tulloch, J., Dudai, Y., and Kelly, P. A. T. (2006). Reconsolidation of spatial memory: differential sensitivity of distinct spatial memory tasks to local inhibition of protein-synthesis 
in dorsal hippocampus following memory retrieval. Neuron 50, 479-489.

Myers, K. M., and Davis, M. (2002). Behavioral and neural analysis of extinction. Neuron 36, 567-584.

Niv, Y. (2007). Cost, benefit, tonic, phasic: what do response rates tell us about dopamine and motivation? Ann. N.Y. Acad. Sci. 1104, 357-376.

O'Doherty, J., Dayan, P., Schultz, J., Deichmann, R., Friston, K., and Dolan, R. J. (2004). Dissociable roles of ventral and dorsal striatum in instrumental conditioning. Science 304, 452-454.

Okamoto, T., Endo, S., Shirao, T., and Nago, S. (2011). Role of cerebellar cortical protein synthesis in transfer or memory trace of cerebellum-dependent motor learning. J. Neurosci. 31, 8958-8966.

Oprisan, S. A., and Buhusi, C. V. (2011). Modeling pharmacological clock and memory patterns of interval timing in a striatal beat-frequency model with realistic, noisy neurons. Front. Integr. Neurosci. 5:52. doi: 10.3389/fnint. 2011.00052

Paule, M. G., Meck, W. H., McMillan, D. E., McClure, G. Y. H., Bateson, M., Popke, E. J., Chelonis, J. J., and Hinton, S. C. (1999). The use of timing behaviors in animals and humans to detect drug and/or toxicant effects. Neurotoxicol. Teratol. 21, 491-502.

Pennartz, C. M. A., Berke, J. D., Graybiel, A. M., Ito, R., Lansink, C. S., can der Meer, M., Redish, A. D., Smith, K. S., and Voorn, P. (2009). Corticostriatal interactions during learning, memory processing, and decision making. J. Neurosci. 29, 12831-12838.

Penney, T. B., Gibbon, J., and Meck, W. H. (2000). Differential effects of auditory and visual signals on clock speed and temporal memory. J. Exp. Psychol. Hum. Percept. Perform. 26, 1770-1787.

Penney, T. B., Gibbon, J., and Meck, W. H. (2008). Categorical scaling of duration bisection in pigeons (Columba livia), mice (Mus musculus), and humans (Homo sapiens). Psychol. Sci. 19, 1103-1109.

Pleil, K. E., Cordes, S., Meck, W. H., and Williams, C. L. (2011). Rapid and acute effects of estrogen on time perception in male and female rats. Front. Integr. Neurosci. 5:63. doi: 10.3389/fnint.2011.00063

Portugal, G., Wilson, A. G., and Matell, M. S. (2011). Behavioral sensitivity of temporally modulated striatal neurons. Front. Integr. Neurosci. 5:30. doi: 10.3389/fnint.2011.00030

Rakitin, B. C., Gibbon, J., Penney, T. B., Malapani, C., Hinton, S. C., and Meck, W. H. (1998). Scalar expectancy theory and peakinterval timing in humans. J. Exp. Psychol. Anim. Behav. Process. 24, 15-33.

Ray, D., and Bossaerts, P. (2011). Positive temporal dependence of the biological clock implies hyperbolic discounting. Front. Neurosci. 5:2. doi: $10.3389 /$ fnins.2011.00002

Reading, P. J., and Dunnett, S. B. (1991). The effects of excitotoxic lesions of the nucleus accumbens on a matching to position task. Behav. Brain Res. 46, 17-29.

Reading, P. J., Dunnett, S. B., and Robbins, T. W. (1991). Dissociable roles of the ventral, medial and lateral striatum on the acquisition and performance of a complex visual stimulus-response habit. Behav. Brain Res. 45, 147-161.

Redgrave, P., Prescott, T. J., and Gurney, K. (1999). Is the shortlatency dopamine response too short to signal reward error? Trends Neurosci. 22, 146-151.

Robbins, T. W., and Brown, V. J. (1990). The role of the striatum in the mental chronometry of action: a theoretical review. Rev. Neurosci. 2, 181-211.

Robbins, T. W., and Everitt, B. J. (2007). A role for mesencephalic dopamine in activation: commentary on Berridge (2006). Psychopharmacology 191, 433-437.

Roberts, S. (1993). "Use of independent and correlated measures to divide a time-discrimination mechanism into parts," in Attention and Performance: XIV. Synergies in Experimental Psychology, Artificial Intelligence, and Cognitive Neuroscience, eds D. E. Meyer and S. Kornblum (Cambridge, MA: MIT Press), 589-610.

Rodríguez-Gironés, M. A., and Kacelnik, A. (1999). Behavioral adjustment to modification in the temporal parameters of the environment. Behav. Process. 45, 173-191.

Roesch, M. R., Singh, T., Brown, P. L., Mullins, S. E., and Schoenbaum, G. (2009). Ventral striatal neurons encode the value of the chosen action in rats deciding between differently delayed or sized rewards. J. Neurosci. 29, 13365-13376.

Routtenberg, A. (2008). The substrate for long-lasting memory: if not protein synthesis, then what? Neurobiol. Learn. Mem. 89, 225-233.
Rudebeck, P. H., Walton, M. E., Smyth, A. N., Bannerman, D. M., and Rushworth, M. F. S. (2006). Separate neural pathways process different decision costs. Nat. Neurosci. 9 1161-1168.

Rudy, J. W. (2008). Is there a baby in the bathwater? Maybe: some methodological issues for the de novo protein synthesis hypothesis. Neurobiol. Learn. Mem. 89, 219-224.

Rudy, J. W., and Sutherland, R. J. (2008). Is it systems or cellular consolidation? Time will tell. An alternative interpretation of the Morris group's recent science paper. Neurobiol. Learn. Mem. 89, 366-369.

Sadowski, R. N., Canal, C. E., and Gold, P. E. (2011). Lidocaine attenuates anisomycin-induced amnesia and release of norepinephrine in the amygdala. Neurobiol. Learn. Mem. 96, 136-142.

Shea-Brown, E., Rinzel, J., Rakitin, B. C., and Malapani, C. (2006). A firing rate model of Parkinsonian deficits in interval timing. Brain Res. 1070, 189-201.

Silva, K. M., and Timberlake, W. (2005). A behavior systems view of the organization of multiple responses during a partially or continuously reinforced interfood clock. Learn. Behav. 33 , 99-110.

Simen, P., Balci, F., deSouza, L., Cohen, J. D., and Holmes, P. (2011). A model of interval timing by neural integration. J. Neurosci. 31, 9238-9253.

Smith, N. J., Horst, N. K., Liu, B., Caetano, M. S., and Laubach, M (2010). Reversible inactivation of rat premotor cortex impairs temporal preparation, but not inhibitory control, during simple reaction-time performance. Front Integr. Neurosci. 4:124. doi: 10.3389/ fnint.2010.00124

Stafford, J. M., and Lattal, K. M. (2009). Direct comparisons of the size and persistence of anisomycininduced consolidation and reconsolidation deficits. Learn. Mem. 16 494-503.

Tanaka, S. C., Doya, K., Okada, G., Ueda, K., Okamoto, Y., and Yamawaki, S. (2004). Prediction of immediate and future rewards differentially recruits cortico-basal ganglia loops. Nat. Neurosci. 7, 887-893.

Tanaka, S. C., Schweighofer, N., Asahi, S., Shishida, K., Okamoto, Y., Yamawaki, S., and Doya, K. (2007). Serotonin differentially regulates short- and long-term prediction of rewards in the ventral and dorsal striatum. PLoS One 2:e1333. doi: 10.1371/journal.pone.0001333

Taylor, K. M., Horvitz, J. C., and Balsam, P. D. (2007). Amphetamine affects the start of responding in the peak interval timing task. Behav. Process. 74, 168-175.

Turner, R. S., and Desmurget, M. (2010). Basal ganglia contributions to motor control: a vigorous tutor. Curr. Opin. Neurobiol. 20, 704-716.

Qi, Z., and Gold, P. E. (2009). Intrahippocampal infusions of anisomycin produce amnesia: contribution of increased release of norepinephrine, dopamine, and acetylcholine. Learn. Mem. 16, 308-314. van der Meer, M. A., Johnson, A., Schmitzer-Torbert, N. C., and Redish, A. D. (2010). Triple dissociation of information processing in dorsal striatum, ventral striatum, and hippocampus on a learned spatial decision task. Neuron 67, 25-32.

van Rijn, H., Kononowicz, T. W., Meck, W. H., Ng, K. K., and Penney, T. B. (2011). Contingent negative variation and its relation to time estimation: a theoretical evaluation. Front Integr. Neurosci. 5:91. doi: 10.3389/ fnint.2011.00091

Vink, M., Kahn, R. S., Raemaekers, M. van den Heuvel, M., Boersma, M. and Ramsey, N. F. (2005). Function of striatum beyond inhibition and execution of motor responses. Hum. Brain Mapp. 25, 336-344.

Wächter, T., Röhrich, S., Frank, A., Molina-Luna, K., Pekanovic, A., Hartler, B., Schubring-Giese, M., and Luft, A. R. (2010). Motor skill learning depends on protein synthesis in the dorsal striatum after training. Exp. Brain Res. 200, 319-323.

Wanisch, K., and Wotjak, C. T. (2008). Time course and efficiency of protein synthesis inhibition following intracerebral and systemic anisomycin treatment. Neurobiol. Learn. Mem. 90, 485-494.

Ward, R. D., Kellendonk, C., Kandel, E. R., and Balsam, P. D. (2012). Timing as a window on cognition in schizophrenia. Neuropharmacology 62, 1175-1181.

Ward, R. D., Kellendonk, C., Simpson, E. H., Lipatova, O., Drew, M. R., Fairhurst, S., Kandel, E. R., and Balsam, P. D. (2009). Impaired timing precision produced by striatal D2 receptor overexpression is mediated by cognitive and motivational deficits. Behav. Neurosci. 123, 720-730.

Williamson, L. L., Cheng, R. K., Etchegaray, M., and Meck, W. H. (2008). "Speed" warps time: 
methamphetamine's interactive roles in drug abuse, habit formation, and the biological clocks of circadian and interval timing. Curr. Drug Abuse Rev. 1, 203-212.

Yin, B., and Troger, A. B. (2011). Exploring the 4th dimension: hippocampus, time, and memory revisited. Front. Integr. Neurosci. 5:36. doi: 10.3389/fnint.2011.00036

Yin, H. H., and Knowlton, B. J. (2006). The role of the basal ganglia in habit formation. Nat. Neurosci. Rev. 7, 464-476.
Yin, H. H., Mulcare, S. P., Hilario, M. R., Clouse, E., Holloway, T., Davis, M. I., Hansson, A. C., Lovinger, D. M., and Costa, R. M. (2009). Dynamic reorganization of striatal circuits during the acquisition and consolidation of a skill. Nat. Neurosci. 12, 333-341.

Zauberman, G., Kim, B. K., Malkoc, S. A., and Bettman, J. R. (2009). Discounting time and time discounting: subjective time perception and intertemporal preferences. J. Mark. Res. XLVI, 543-556.
Conflict of Interest Statement: The authors declare that the research was conducted in the absence of any commercial or financial relationships that could be construed as a potential conflict of interest.

Received: 28 June 2011; paper pending published: 12 July 2011; accepted: 28 February 2012; published online: 14 March 2012.

Citation: MacDonald CJ, Cheng R-K and Meck WH (2012) Acquisition of "Start" and "Stop" response thresholds in peak-interval timing is differentially sensitive to protein synthesis inhibition in the dorsal and ventral striatum. Front. Integr. Neurosci. 6:10. doi: 10.3389/fnint. 2012.00010

Copyright (c) 2012 MacDonald, Cheng and Meck. This is an open-access article distributed under the terms of the Creative Commons Attribution Non Commercial License, which permits non-commercial use, distribution, and reproduction in other forums, provided the original authors and source are credited. 